\title{
New insights into the oxidation mechanisms of a ferritic- martensitic steel in high-temperature steam
}

Zhao Shen ${ }^{1, *}$, Kai Chen ${ }^{2}$, Hongbing $\mathrm{Yu}^{3}$, Benjamin Jenkins ${ }^{1}$, Yanru Ren ${ }^{1}$, Naganand Saravanan ${ }^{1}$, Guanze He ${ }^{1}$, Xiaonan Luo ${ }^{1}$, Paul Bagot ${ }^{1}$, Michael P. Moody ${ }^{1}$, Lefu Zhang ${ }^{2}$, Sergio Lozano-Perez ${ }^{1}$

${ }^{1}$ Department of Materials, University of Oxford, Parks Road, OX1 3PH Oxford, UK

${ }^{2}$ School of Nuclear Science and Engineering, Shanghai Jiao Tong University, 800 Dongchuan Road, 200240 Shanghai, China

${ }^{3}$ Department of Engineering Science, University of Oxford, Parks Road, OX1 3PJ Oxford, UK Corresponding author: zhao.shen@materials.ox.ac.uk 
Abstract: The microstructure of the surface oxide film formed on an Fe-9Cr ferritic-martensitic (FM) steel after exposure to deaerated high-temperature steam at $600{ }^{\circ} \mathrm{C}$ for $100 \mathrm{~h}$ has been analyzed in detail by advanced characterization techniques. The surface oxide film has been revealed to have a triplex structure, including an outer oxide layer, an inner oxide layer, and an internal oxide layer. Although the outer and inner oxide layers are continuous, the internal oxide layer has been proved to consist of interconnected metallic and chromite phases, which is a typical feature of internal oxidation. The formation mechanisms of each layer have been discussed, finding that, contrary to what the available space model suggests, an external oxidation is not the controlling oxidation mechanism of F-M steels in high-temperature steam. The higher resolution used in this study confirms that the controlling mechanism is internal oxidation.

Key words: Ferritic-martensitic steel; Internal oxidation; Transmission electron microscopy; Transmission Kikuchi diffraction; Atom probe tomography.

\section{Introduction}

High Cr content Ferritic-Martensitic (F-M) steels, typically ranging from 9 to 12 weight percent $\mathrm{Cr}$, were developed since the early 1930s, originally for applications in the petrochemical industry, and later for the aerospace sector and conventional fossil fuel power generation units [1-5]. Due to the discovery of the phenomenon of irradiation-induced void swelling in austenitic alloys at the end of 1960s [6], F-M steels have also been used to partially replace austenitic alloys in the nuclear industry due to their excellent resistant to void swelling under irradiation conditions [1]. A combination of low cost, good high-temperature strength, high stress corrosion cracking resistance, and low void swelling under irradiation, have contributed to very successful service records in the industries mentioned above, especially in steam-generating power plants, in which the high-temperature steam acts as a heat transfer medium and is very corrosive to the structural materials [2, 5]. To reduce carbon emissions, it is desirable to improve the efficiency of the steam-generating power plants by increasing the operating steam temperature and pressure, such as in the ultra-supercritical coal-fired power plants [7, 8] and supercritical water-cooled nuclear reactors [9-11]. With the increase of operating temperatures $(>600$ ${ }^{\circ} \mathrm{C}$ ), the growth of oxide film on the F-M steels is significantly enhanced [12-25]. The consequences of the thickening and failure of the surface oxides are of increasing concern in these steam-generating power plants. For example, the progressive reduction of heat transfer by thickening oxides can lead to over-heating and failure, and exfoliation of these oxides can result in blocking of tubes or, if the oxide fragments are transported in the steam, erosion of the steam turbine [2].

To improve the service lifetime of the F-M steels in high-temperature steam environments the corrosion rates of the materials should be minimized. The material composition, operating temperature, and content of dissolved oxygen are reported to play critical roles on affecting the corrosion rate [2, 10, 25-28]. Although significant research efforts have been undertaken, the effects of different factors on the materials corrosion remain unclear. For example, in the study of P92 F-M steel in hightemperature steam, the corrosion rate is reported to be accelerated by an increase of dissolved oxygen content [26]. While Ampornrat et al. [25] and Dooley et al. [27] reported that the corrosion rates of F$\mathrm{M}$ steels in high-temperature steam decrease with the increase of dissolved oxygen content (10-300 $\mathrm{ppb}$ ) first and then increase (300-2000 ppb). Since individual factors can affect the corrosion differently, all the factors should be optimized to mitigate the materials corrosion in high-temperature steam. This requires a mechanistic understanding of the materials corrosion under the high-temperature steam conditions. 
To date, various oxidation mechanisms or models have been proposed to explain the formation of a duplex surface oxide film on alloys after exposure to high-temperature environments, not only in steam $[2,10,12,13,15,19,20]$ but also in sulphur [29], carbon dioxide [30-32], and liquid metal [33-35]. These models describing the formation of dual-layers of surface oxide can be mainly classified into three groups: 1) dissociation of external oxide layer [36]; 2) different elemental diffusion rates [37, 38]; 3) available space model [19, 20, 34, 35, 39-41]. The first model states that the surface oxide is formed by the outward migration of cations. The dissociation of the surface oxide into two layers occurs at some point and leads to the formation of dual-layers of surface oxide. As a result, the interface between the two layers is not consistent with the original water-alloy interface, which contradicts to the experimental observations in $[10,12-20,34,35,39-41]$. The second model suggests that the formation of the dual-layers of surface oxide is due to the varied outward diffusion rates of different cations [42], as is the case in Fe-Cr steels, where the diffusion of $\mathrm{Cr}^{3+}$ is much slower than $\mathrm{Fe}^{2+/ 3+}[37$, 38]. Since the original water-alloy interface does not correspond to the outer-inner oxide layer interface $[10,12-20,34,35,39-41]$, this model can also be ruled out. In contrast to the other models, the available space model appears to describe the formation of two-layers of surface oxide more realistically [19, 20, 34, 35, 39-41]. This model considers the simultaneous diffusion of oxidant and cations, and directly links the formation of outer and inner oxide layers to the cation outward diffusion and oxidant inward diffusion, respectively. In addition, it predicts the outer-inner oxide layer interface to coincide with the original water-alloy interface, which is consistent with the experimental observations [10, 12-20, 34, 35, 39-41]. As a result, the available space model is attracting more and more attention. However, this model accounts neither for the formation of a third oxide layer between the inner oxide layer and metal matrix, nor for the inhomogeneous chemical composition and microstructure in the inner oxide layer. Due to the difficulties in achieving the necessary experimental scale of analysis (micro-to-atomic), a mechanistic understanding of the surface oxidation in hightemperature environments has not been achieved and requires further investigation.

Recent developments in high-resolution microscopy techniques, enabling a more detailed characterization of material microstructure, have significantly advanced our understanding of a range of previously unresolved phenomena [43-47]. In this study, we use a combination of: microscale Secondary Electron Microscopy (SEM), Energy Dispersive X-ray (EDX), and Electron Back Scattered Diffraction (EBSD), nanoscale on-axis Transmission Kikuchi Diffraction (TKD), Transmission Electron Microscopy (TEM), Electron Energy Loss Spectroscopy (EELS), atomic-scale Atom Probe Tomography (APT), and High-Angle Annular Dark Field (HAADF) imaging to conduct a direct study on the oxide formed on a Fe-9Cr F-M steel after exposure to low-oxygen, high-temperature steam. The unprecedented micro-to-atomic scale observations captured in this study provide direct evidence to unveil the evolution of surface oxide during exposure. Underpinned by this evidence, new insights about the oxidation mechanisms of F-M steel in high-temperature steam shall be obtained.

\section{Experimental}

\subsection{Materials}

The Fe-9Cr F-M steel used in this study was provided by Bao-Steel Corporation, which was normalized at $1066{ }^{\circ} \mathrm{C}$ and tempered at $790{ }^{\circ} \mathrm{C}$ prior to the exposure testing. The chemical composition is $8.93 \mathrm{Cr}, 0.45 \mathrm{Mn}, 0.82 \mathrm{Mo}, 0.23 \mathrm{Ni}, 0.092 \mathrm{C}, 0.002 \mathrm{~S}, 0.25 \mathrm{Si}, 0.012 \mathrm{P}, 0.18 \mathrm{Cu}, 0.21 \mathrm{~V}$, and balance $\mathrm{Fe}$ (wt. \%). The SEM morphology of the Fe-9Cr steel with a mirror-finished surface is shown in Fig. 1a. To reveal the crystallographic information of the steel, EBSD was conducted. The crystallographic orientation information for the ferrite phase (ferrite and martensite are not easily separated by EBSD 
and just one phase was used in these maps) is shown in the Euler map (Fig. 1b). It is seen that there is no texture in the metal matrix prior to the exposure tests. The distribution of grain shapes is shown in Fig. 1c, and the related grain size distribution profile is shown in Fig. 1d. It is seen that the grain sizes vary from just under $2 \mu \mathrm{m}$ to $14 \mu \mathrm{m}$. The average grain size is measured to be around $5.6 \mu \mathrm{m}$.
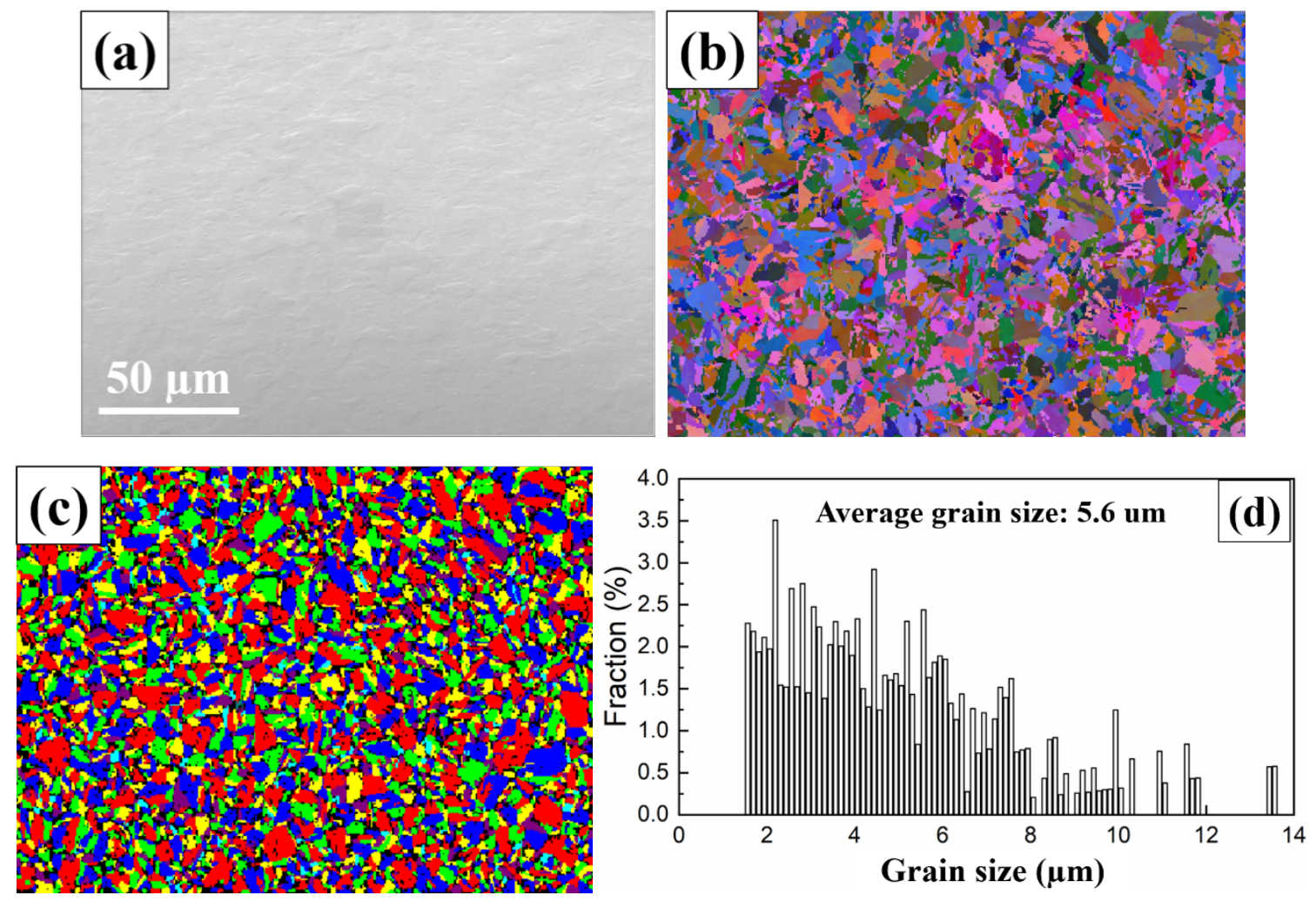

Figure 1. EBSD analysis of the Fe-9Cr F-M steel (step size $=0.5 \mu \mathrm{m})$ : a) SEM SE image; b) Euler map; c) grain shape map; d) grain size distribution profile.

\subsection{Autoclave testing}

The coupons used for corrosion test were machined from a plate to dimensions of $15 \mathrm{~mm} \times 30 \mathrm{~mm} \times 2$ $\mathrm{mm}$, followed by surface polishing up to 1.0 micron diamond suspension solution. Then they were subsequently cleaned with acetone and rinsed with de-ionized water in ultrasonic cleaner. The corrosion test was carried out in a circulating autoclave system with a $1.5 \mathrm{~L}$ autoclave made of Nibased alloy 625, a water chemistry controlling unit, and a temperature controller, as shown schematically in Fig. 2. The coupons were exposed to steam at a temperature of $600^{\circ} \mathrm{C}$ under a pressure of $25 \mathrm{MPa}$ for various lengths of time and weight gain and oxide thickness measurements are shown in Fig. 3. As can be seen, the oxide growth follows a sub-parabolic rate (with a $\sim 0.4$ exponent). The coupon extracted after a $100 \mathrm{~h}$ exposure was used for all the results presented in this work unless specifically stated. The circulating flow rate was controlled at about $3 \mathrm{~L} / \mathrm{h}$ by high pressure metering pump combined with a high precision back pressure regulator, which provided about 2 times of volumetric refresh rates of water in the autoclave. Dissolved oxygen (DO) concentrations at autoclave inlet and outlet were monitored and controlled below $10 \mathrm{ppb}$ by continuous bubbling of high purity argon gas in the water tank. Outlet water from the autoclave was purified by the nuclear grade mixed resin bed. The conductivities of the inlet and outlet water were monitored and kept at about 0.056 and $0.2 \mu \mathrm{S} / \mathrm{cm}$, respectively. 


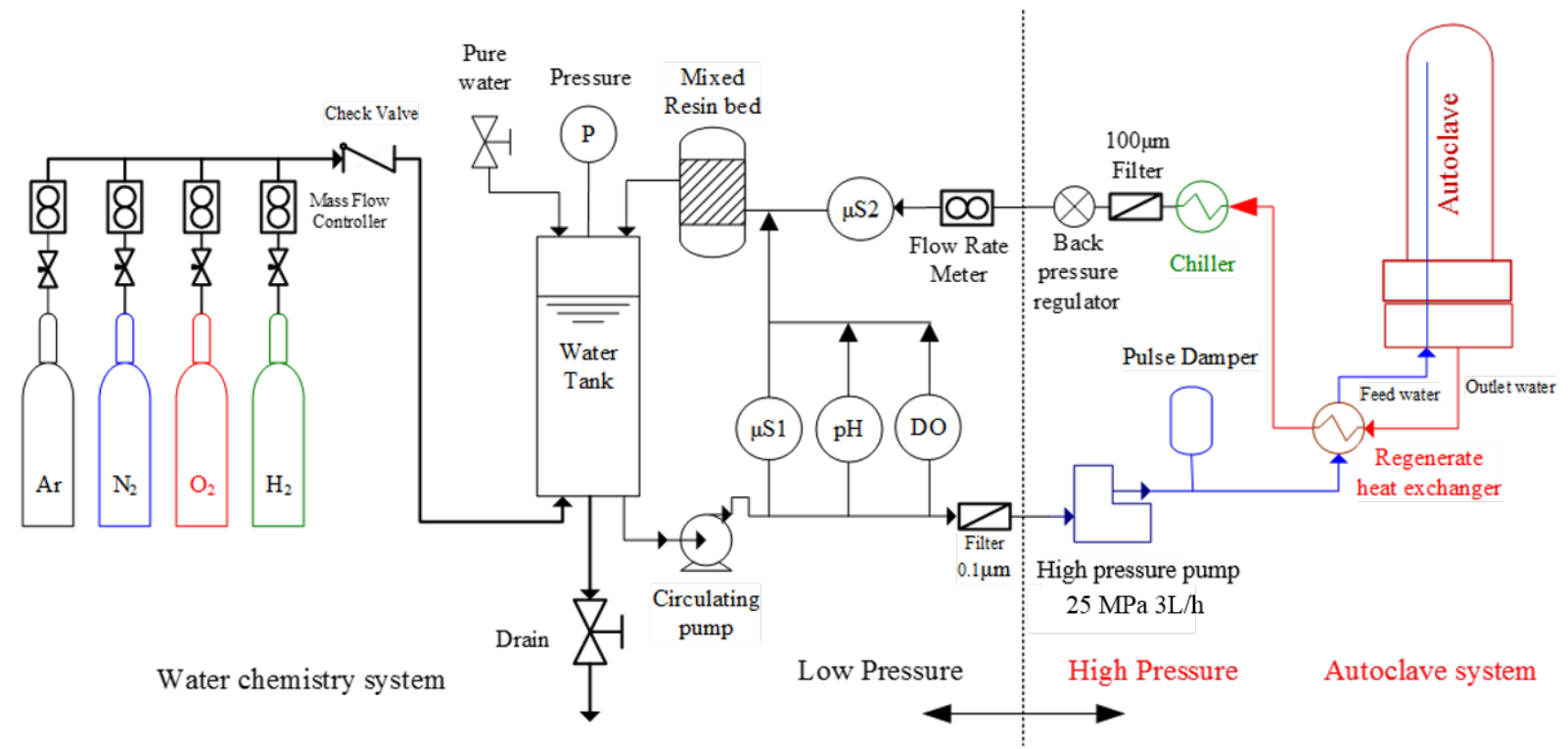

Figure 2. Schematic of the high-temperature corrosion test system.

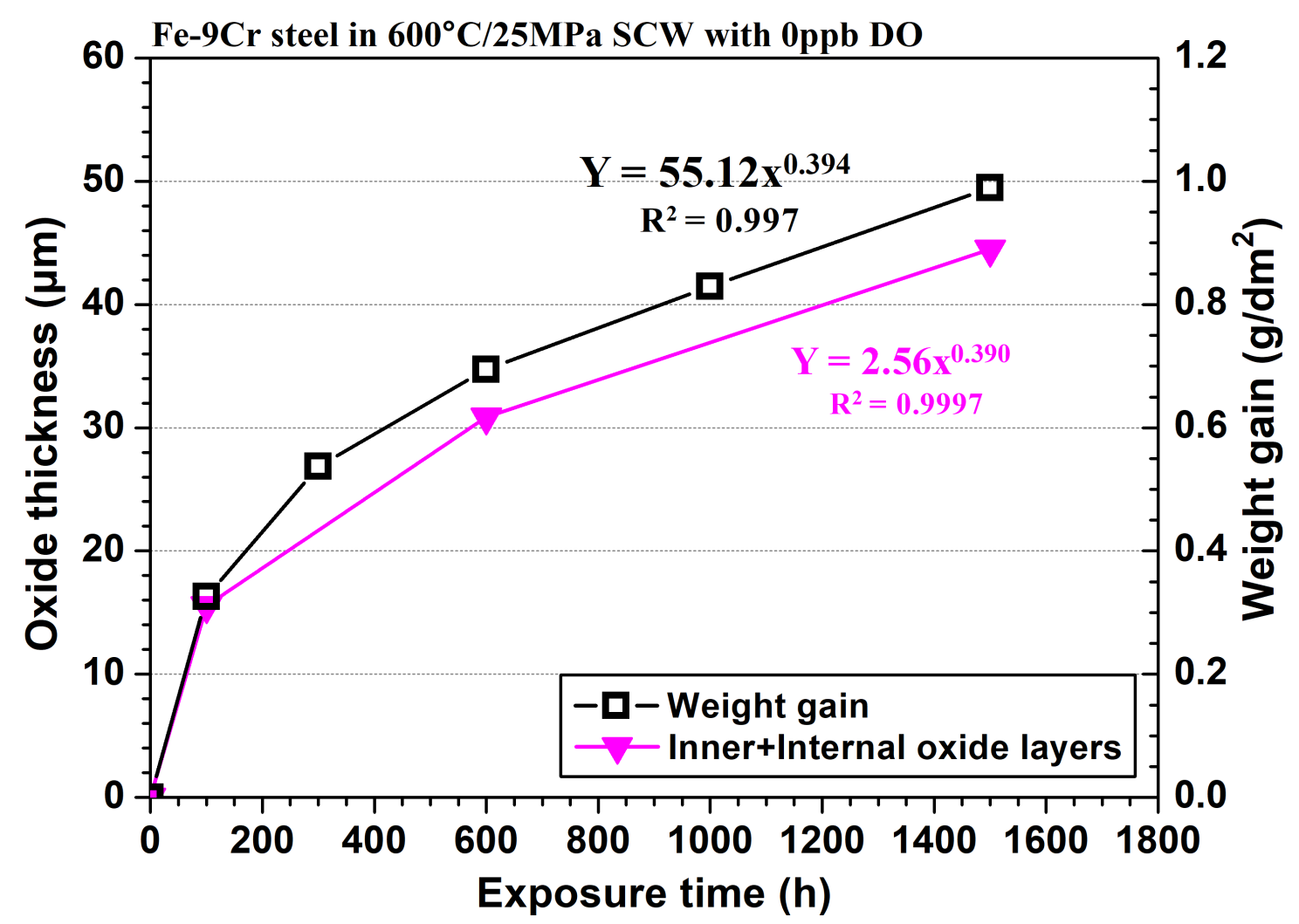

Figure 3. Evolution of measured oxide thickness (Inner+Internal layers) and weight gain with exposure time.

\subsection{Characterization techniques}

The morphology of the cross-section of the surface oxide film was examined by SEM using a Field Emission Gun Zeiss Crossbeam 540 equipped with Oxford Instruments X-max 150 EDX detector and NordlysMax 3 EBSD detector systems. Chemical composition of the surface oxide film was examined 
by low-energy EDX at a working distance of $5.2 \mathrm{~mm}$, a beam voltage of $5 \mathrm{kV}$ and a $2 \mathrm{nA}$ probe current. Due to the decrease of accelerating voltage $(5 \mathrm{kV}$ vs. $20 \mathrm{kV})$, both the spatial resolution and signal-tonoise ratio are significantly increased. More details can be found in [48]. To examine the crystallographic orientation of the surface oxide film, EBSD maps were obtained at a working distance of $18 \mathrm{~mm}$ and a sample tilt of $70^{\circ}$, with a beam voltage of $20 \mathrm{kV}$ and $15 \mathrm{nA}$ probe current. The step size was set to $200 \mathrm{~nm}$. The data was subsequently post-processed by the Oxford Instrument software Channel 5. Pattern quality and IPF maps were calculated automatically by the software.

The site-specific TEM samples were prepared by Focused Ion Beam (FIB). A single beam FEI FIB200 equipped with a static micromanipulator was used for trenching and in-situ lift-out. A dual beam Zeiss NVision 40 FIB-SEM was subsequently used for thinning sample to a thickness less than $50 \mathrm{~nm}$. Since FIB milling could introduce significant damage on the sample surface, final low energy cleaning ( $5 \mathrm{kV}$, $250 \mathrm{pA}$ ) with FIB was performed on both sides of the thin foil after a conventional milling to minimize the damage.

On-axis TKD analysis was performed on the TEM samples using a Zeiss Merlin FEG-SEM equipped with a Bruker e-flash high-resolution EBSD detector with an Optimus TKD head that allows for better spatial resolution with minimal sample drift. The sample was held normal to the electron beam at a working distance of $5 \mathrm{~mm}$ and Kikuchi patterns captured underneath with a horizontal phosphor screen at an accelerating voltage of $20 \mathrm{kV}$ and a probe current of $1.5 \mathrm{nA}$. The step size was set to $5 \mathrm{~nm}$. The data was subsequently post-processed by Channel 5 software to obtain pattern quality, phase, grain shape, IPF maps.

HAADF imaging and EELS were conducted with an aberration-corrected JEOL ARM200F (cold-field emission gun) operating at $200 \mathrm{kV}$ and equipped with a Quantum Gatan image filter spectrometer. The annular angular range for HAADF imaging was 73-236 mrad. EELS spectra (low- and core-loss) were acquired correcting the spatial drift and recalibrated in energy using the zero loss peak as a reference. Principal components analysis (for denoising) was performed using Hyperspy 1.1 (open source) software. The convergence and collection half-angles were 31 and $41 \mathrm{mrad}$, respectively. EELS quantification was performed in Digital Micrograph by the background subtraction method. The relatively low thickness of all areas analyzed $(\sim 40 \mathrm{~nm})$ allow for a reliable quantification without removing plural scattering. This was checked for regions of known composition (e.g. metal matrix).

APT samples were prepared by FIB, using a dual beam Zeiss NVision 40 FIB-SEM. Samples were trenched and lifted out and attached to individual posts on a silicon microtip coupon. FIB was then used to mill the sample into a sharp needle, with an approximate tip radius of $50 \mathrm{~nm}$. Finally, a low energy cleaning step $(2 \mathrm{kV}, 300 \mathrm{pA})$ was applied to the needle to minimize surface damage. APT analysis was performed using a LEAP $5000 \mathrm{XR}$, with a detection efficiency of $52 \%$. Samples were analysed using a laser energy (UV - $355 \mathrm{~nm}$ laser) of $45 \mathrm{pJ}$, sample temperature of $40 \mathrm{~K}$, a pulse frequency of $200 \mathrm{kHz}$ and a detection rate of $0.2 \%$. The APT data was processed using IVAS 3.8.4, with the needle shape estimated using a voltage reconstruction. Peak overlaps were solved using AtomProbeLab [49] which implements the methods described in [50].

\section{Results}

\subsection{Microscale characterization}

\subsubsection{Chemical composition analysis by SEM-EDX}


The 100h exposure coupon was polished to expose the cross-section of the surface oxide film. SEMEDX analysis shows that except from the Fe-rich outer oxide layer and $\mathrm{Cr}$-rich inner oxide layer, there was a third oxide layer between the inner oxide layer and the metal matrix, as shown in Fig. 4a. The third oxide layer is defined as an internal oxide layer in the present study. Compared with the inner oxide layer, the internal oxide layer contained much lower content of oxygen. Further observation reveals that the distribution of oxygen in this layer was not uniform.

To reveal the qualitative (volume content) and quantitative (atomic ratio) distribution of chemical composition across the surface oxide film, low-energy EDX line-scanning was conducted, as shown in Fig. 4b. The qualitative line-scan shows that there was a significant loss of Fe in the inner oxide layer. The loss of $\mathrm{Fe}$ was also observed in the internal oxide layer, although the extent was much less than in the inner oxide layer. Further observation shows that there was a Fe content gradient in the internal oxide layer, decreasing from the metal matrix towards the inner oxide layer. All the loss of Fe in the inner and internal oxide layers is believed to be consumed by the outward diffusion towards the outer oxide layer-steam interface during exposure, forming the Fe-rich outer oxide layer. Compared with the decline of $\mathrm{Fe}$ in the inner and internal oxide layers, the content of $\mathrm{Cr}$ was nearly the same with that in the metal matrix. The content of oxygen nearly remained constant in the outer and inner oxide layer, while decreased gradually towards the metal matrix. The quantitative line-scan shows that the outer oxide layer appeared to be composed of $\mathrm{Fe}_{3} \mathrm{O}_{4}$, while the chemical composition of the inner and internal oxide layers was not compatible with any common phase, which was usually reported to be $\mathrm{Cr}-\mathrm{Fe}$ spinel $\mathrm{Fe}_{3-\mathrm{x}} \mathrm{Cr}_{\mathrm{x}} \mathrm{O}_{4}[1-3,10,35]$.

It is necessary to point out that in the analysis of EDX qualitative line profiles, we assume that the EDX signal intensity is proportional to numbers of atoms in a given volume. This assumption is usually believed to be not accurate due to the absorption and fluorescence effects. However, the voltage we used for the EDX line-scanning is $5 \mathrm{kV}$, which is much lower than the normal $20 \mathrm{kV}$ voltage. The decreased voltage has been proved to decrease the interaction volume remarkably [48], resulting in much smaller absorption and fluorescence effects. As a result, we believe the EDX signal intensities obtained at low energy can be used to analyse the proportional numbers of related atoms in a given volume in a qualitative manner. This assumption can be supported by the measured constant $\mathrm{Cr}$ content in the metal matrix and the inner and internal oxide layers since $\mathrm{Cr}$ is reported to have much slower diffusion rate than $\mathrm{Fe}$ and remains in the inner and internal oxide layers during the process of oxidation [35]. In addition, the equal volume concentration of $\mathrm{Cr}$ in the inner oxide layer and the metal matrix has also been reported by other researchers $[35,51,52]$. 


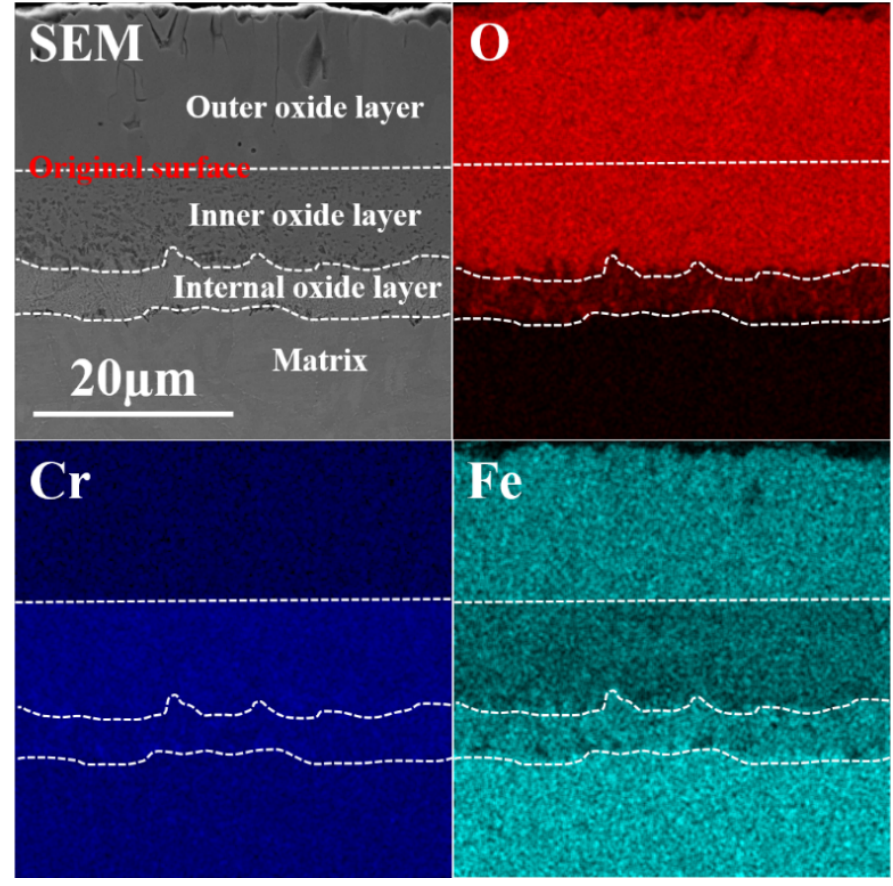

(a)

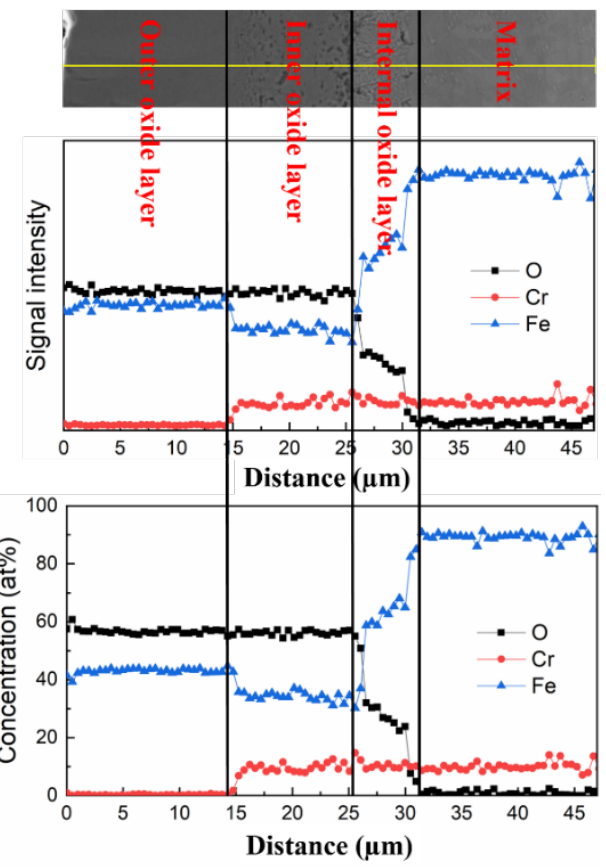

(b)

Figure 4. (a) SEM SE image and EDX elemental maps showing a triple-layered surface oxide scale: a Fe-rich outer oxide layer, a Cr-rich inner oxide layer, and an internal oxide layer; (b) EDX line-scan showing the qualitative and quantitative distribution of chemical composition across the surface oxide film.

\subsubsection{Crystallographic analysis by SEM-EBSD}

Fig. 5a shows the Forward Scatter Detector (FSD) image of the cross-section of the surface oxide film. SEM-EBSD analysis reveals that the outer oxide layer consisted of columnar magnetite crystallites while the inner oxide layer was not well-indexed (Fig. 5b). The inner oxide layer was widely believed to be composed of nano-crystallites $[10,15,18,20,34]$, and the resolution of the traditional EBSD might be not able to resolve the nano-sized features. Although the nano-sized features had not been properly indexed, some large grains can still be observed. The positions of the large grains were very likely correlated with the positions of the original metal grains, which suggested that the oxides in the inner oxide layer might have not been fully nano-crystallized.

Interestingly, the third oxide layer retained the same crystallographic information as the underlying metal matrix. Similar results have also been reported by many other researchers $[1-3,10,17,19,20$, $51,52]$. Due to the lack of awareness of the importance of this observation, the formation and existence of this layer have not been fully investigated. To date, there is not a consensus on the name of the third oxide layer. Both diffusion layer [19, 20] and transition layer [17] have been widely used in the literature. Due to the increase of characterization resolution, Tan et al. [15] and Ye et al. [51] named the third layer as an internal oxide layer based on their experimental observations, although the formation mechanism of this layer was not fully explained. In the current study, the third layer was also referred to as internal oxide layer according to our observations, which will be shown and discussed later. 


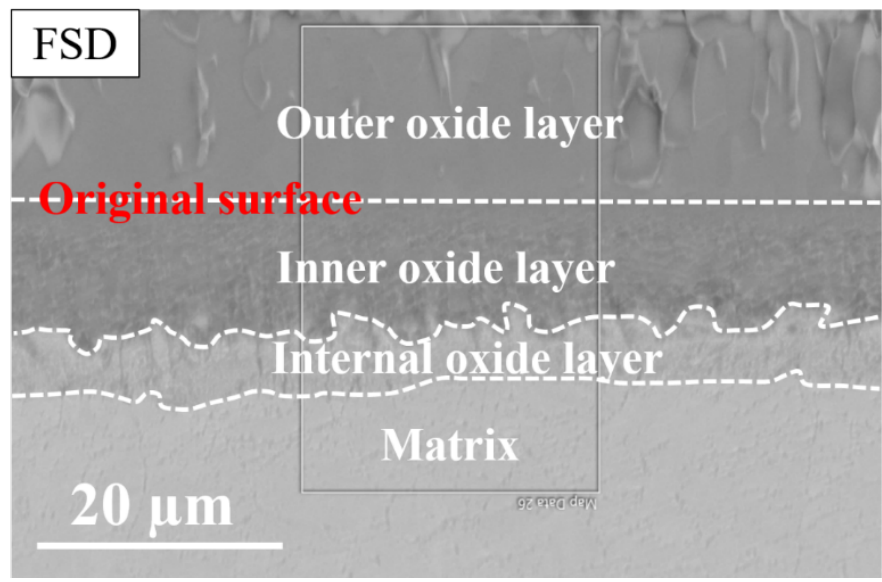

(a)

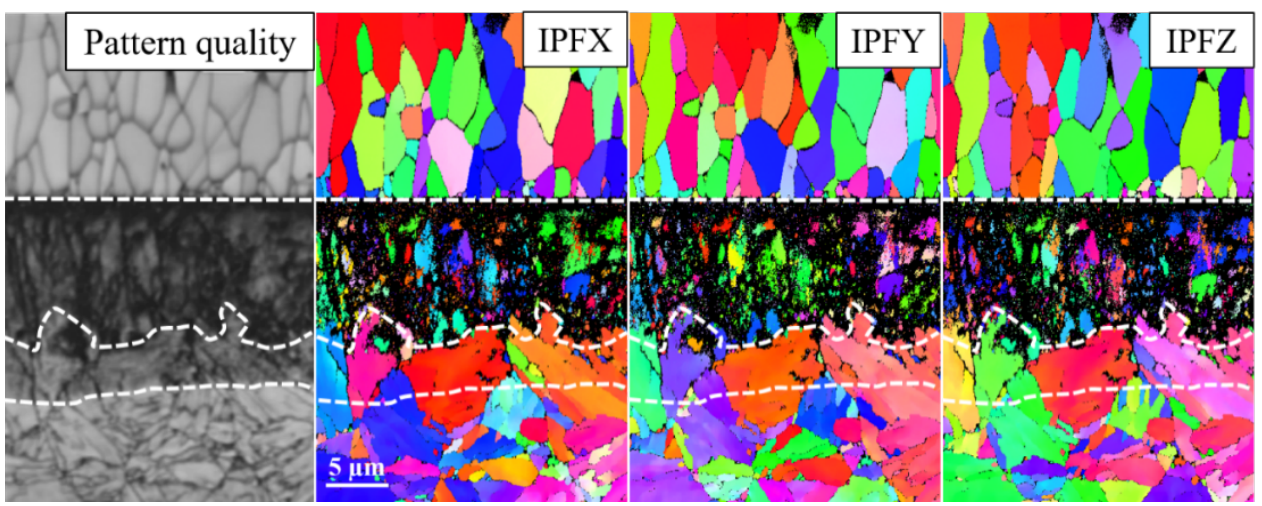

(b)

Figure 5. (a) FSD image showing a triple-layered structure of the surface oxide scale; (b) pattern quality and IPF maps (from left to right, step size $=200 \mathrm{~nm}$ ).

\subsection{Nano-to-atomic scale characterization}

Due to the lack of resolution of the SEM-EDX/EBSD analyses, neither an accurate chemical composition nor crystallographic information of the inner and internal oxide layers can be obtained and require higher resolution analyses. To study the inner and internal oxide layers in its entirety, two site-specific TEM samples and two site-specific APT needles were prepared from different regions. The positions of the two TEM samples and two APT needles relative to the surface oxide cross-section are shown in Fig. 6a. The schematic of the orientation of the TEM samples and APT needles relative to the oxidized coupon is shown in Fig. 6b. Since the growth of the inner and internal oxide layers is due to the inward migration of oxygen and outward migration of cations [19, 20, 34, 35, 39-41], the different depths of the oxides suffered different oxidation times, the greater the oxide depth the shorter oxidation time. As a result, four different regions were selected from the two TEM foils to represent the oxides subjected to different oxidation times. As shown in Fig. 6a, the oxidation times for the four regions shown are: Region $1<$ Region $2<$ Region $3<$ Region 4 . To study the evolution of chemical composition distribution and crystallographic information within the oxidation time, nano-to-atomic scale analytical TEM (ATEM), APT, and TKD were conducted. 


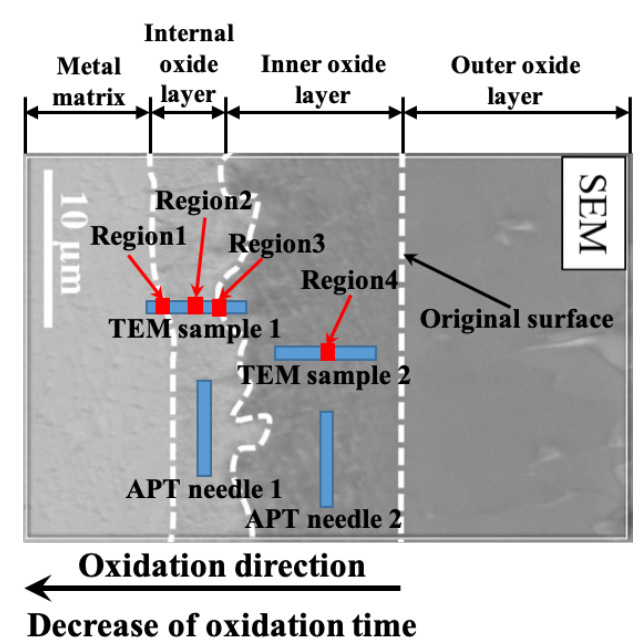

(a)

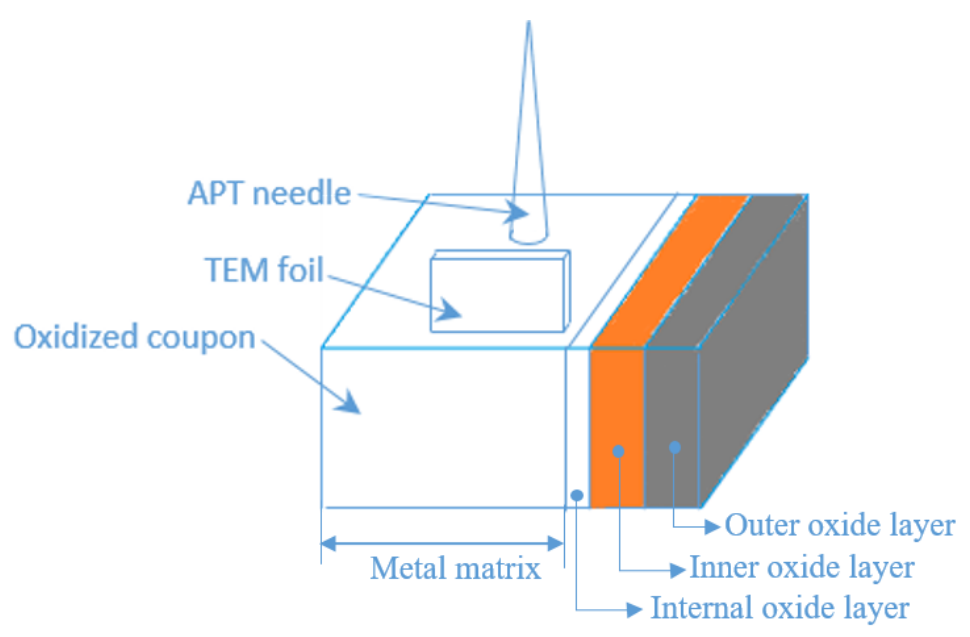

(b)

Figure 6. (a) Illustration of the positions of two TEM samples and two APT needles on the crosssection of surface oxide film: TEM sample 1 was prepared from the region across the internal oxide layer; TEM sample 2 was prepared from the centre of the inner oxide layer; APT needle 1 was prepared from the middle region of the internal oxide layer; APT needle 2 was prepared from the middle region of the inner oxide layer. (b) Schematic of the orientation of the two TEM foils and two APT needles relative to the oxidized coupon.

\subsubsection{Chemical composition analysis by ATEM}

\section{(a) Internal oxide layer-matrix interface}

Region 1 was located at the internal oxide layer-matrix interface and the oxide in this region was used to represent the initial stage of oxidation. Since the HAADF image is very sensitive to the average atomic number $(\mathrm{Z})$ and sample thickness, assuming a local uniform thickness, darker regions are indicative of lower atomic density. This assumption is reasonable for FIB samples and has been proved by calculating and comparing the local sample thickness by EELS. As a result, it is easy to distinguish the oxides from the metal due to their different average Z. As shown in Fig. 7a, the left-half and righthalf of Region 1 represents a part of unaffected metal matrix and internal oxide layer, respectively. It is seen that the oxides around the oxidation front were not continuous and were distributed discretely. The dispersed oxide precipitates showed a needle-shape without any specific orientations according to the HAADF image. EELS signal intensity (qualitative) maps show that the oxide precipitates were enriched in $\mathrm{Cr}$ and depleted in Fe (Fig. 7b). EELS line-scanning was also conducted. The qualitative (proportional to number of atoms in projection) line profile shows that the metal around the oxide precipitates contained a lower amount of $\mathrm{Cr}$ than the unaffected metal matrix (Fig. 7c). The lower $\mathrm{Cr}$ could be explained by the formation of neighbouring $\mathrm{Cr}$-rich oxide precipitates. The EELS quantitative (atomic concentration in projection) line profile shows that the chemical composition of the different oxide precipitates was variable (Fig. 7d). This is very likely because most of the oxide precipitates were smaller in diameter than the thickness of the TEM sample $(\sim 50 \mathrm{~nm})$. The composition measured from an individual precipitate would always be a mixture of metal and oxide. However, the oxide precipitate that was larger than the sample thickness was occasionally observed ( $\sim 100 \mathrm{vs} . \sim 50 \mathrm{~nm})$, as highlighted by a blue dashed circle in Fig. 7a. The chemical composition measured from this precipitate was, therefore, believed to be reliable. As shown in Fig. 7d, the atomic ratios of the oxide precipitate highlighted by the blue dashed circle were very similar to chromite $\left(\mathrm{FeCr}_{2} \mathrm{O}_{4}\right)$. Atomicresolution HAADF imaging was also conducted on the oxide precipitate. The HAADF image and 
related simulated chromite atomic structure further proved a chromite-type spinel (Fig. 7e). It should be noted that, along a $<100>$ type zone axis, all atomic columns showing only $\mathrm{O}$ atoms (red) in the model will also have $\mathrm{Cr}$ atoms underneath in projection. For this reason, and since $\mathrm{Fe}$ and $\mathrm{Cr}$ have a very similar atomic number, their HAADF intensity is also similar. With this experimental evidence, the oxide precipitates formed at the early stage were believed to be chromite.

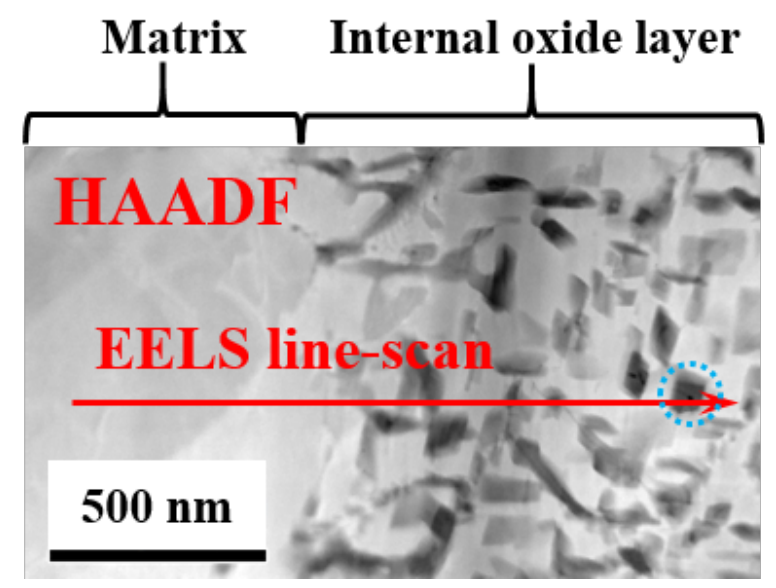

(a)

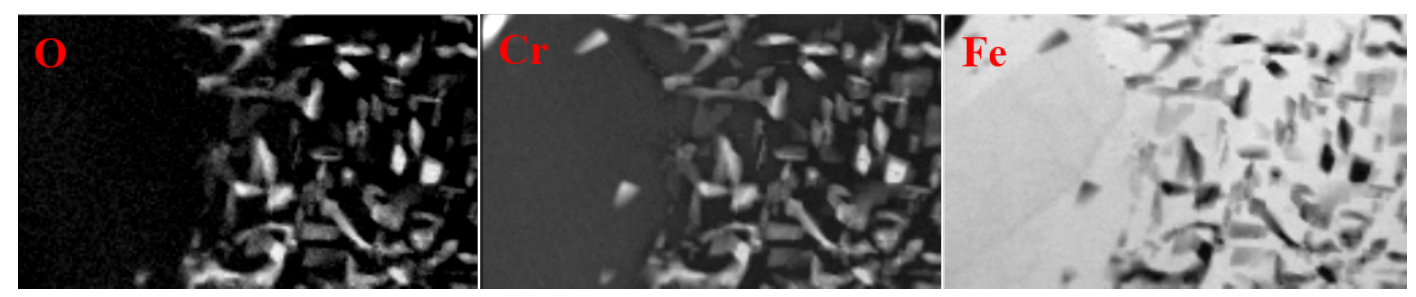

(b)

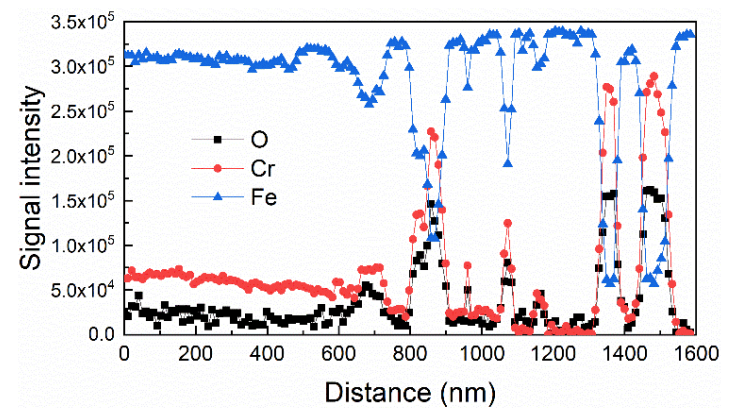

(c)

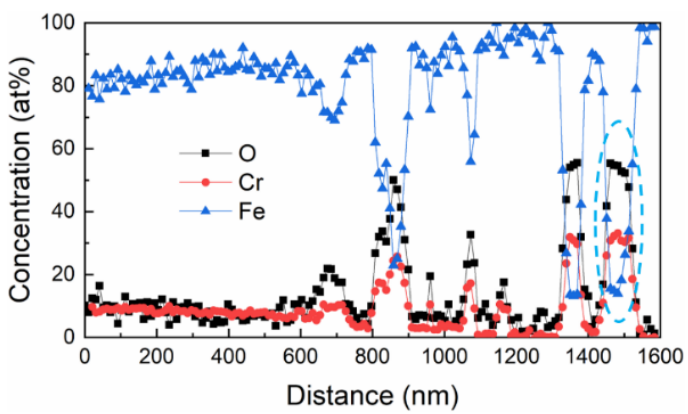

(d)

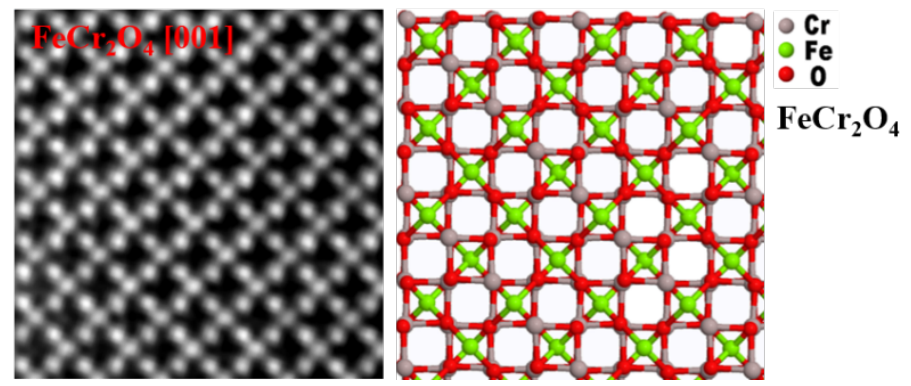

(e)

Figure 7. Morphology and chemical composition distribution around the internal oxide layer-matrix interface (TEM sample 1, Region 1). (a) HAADF image showing the morphology around the internal oxide layer-matrix interface; (b) qualitative EELS chemical composition mapping showing the distribution of $\mathrm{O}, \mathrm{Cr}$, and $\mathrm{Fe}$; (c) qualitative and (d) quantitative EELS line profiles showing the 
distribution of $\mathrm{O}, \mathrm{Cr}$, and Fe. (e) Atomic-resolution HAADF image and related simulated atomic structure of chromite showing that the oxide precipitate marked by a blue dashed circle in (a) is consistent with chromite-type spinel.

\section{(b) Internal oxide layer}

Region 2 was around $3 \mu \mathrm{m}$ away from the oxidation front. Compared with Region 1, Region 2 had suffered longer time of oxidation. Fig. 8a shows that the oxides in this region were still dispersed. Interestingly, although the oxide precipitates also showed a needle-shape morphology, they appeared to precipitate along specific orientations. It is necessary to point out that Region 1 and Region 2 were located in different matrix grains. EELS signal intensity maps show that the oxide precipitates were also enriched in $\mathrm{Cr}$ and depleted in Fe (Fig. 8b). EELS qualitative line profile shows that the metal surrounding these precipitates was nearly made of pure Fe, with almost all the Cr now oxidized (Fig. 8c). EELS quantitative line profile shows that the chemical composition varied between precipitates (Fig. 8d), which was also believed to be due to the overlap between the oxides and surrounding metal. A large oxide precipitate was also observed in Region 2 (as highlighted by the blue dashed circle). Both the atomic-resolution image and the atomic ratio (Fig. 8d) measured from this precipitate suggested that the oxide precipitates in this region were also composed of chromite $\left(\mathrm{FeCr}_{2} \mathrm{O}_{4}\right)$.

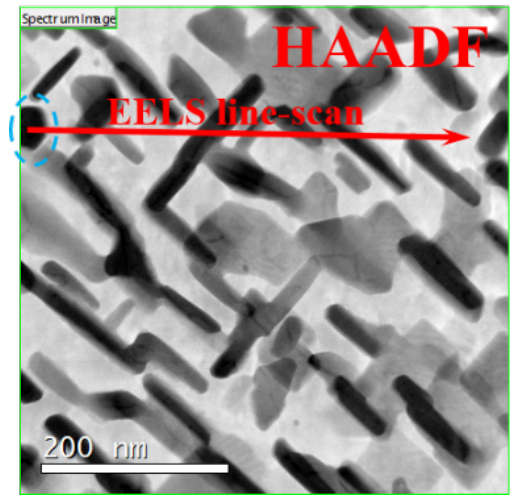

(a)

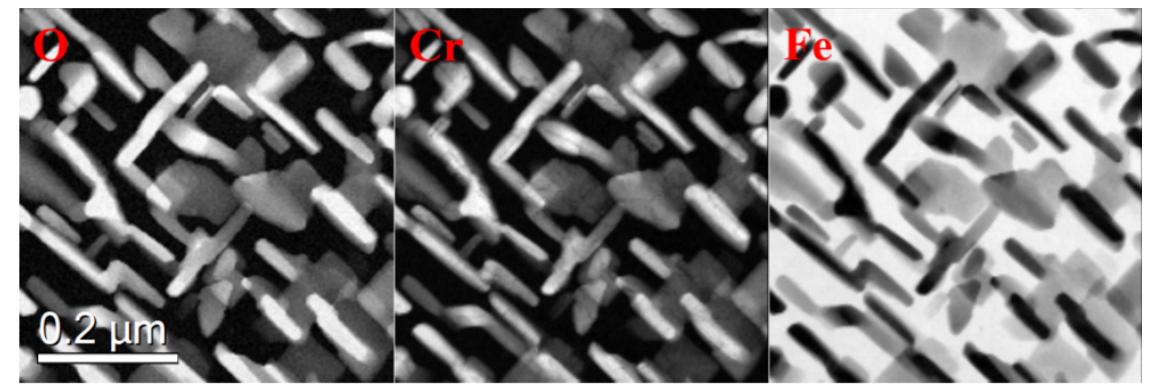

(b)

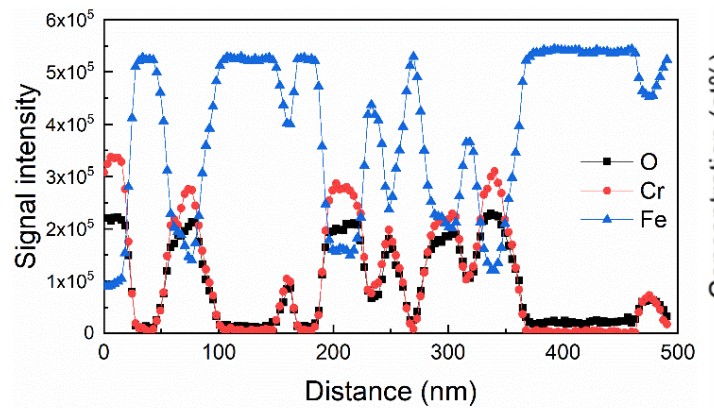

(c)

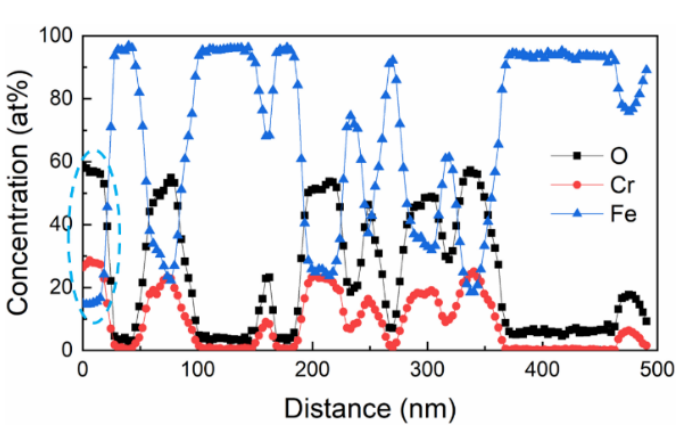

(d) 
Figure 8. Morphology and chemical composition distribution in the internal oxide layer (TEM sample 1, Region 2). (a) HAADF image showing the morphology in the internal oxide layer; (b) qualitative EELS chemical composition mapping showing the distribution of $\mathrm{O}, \mathrm{Cr}$, and $\mathrm{Fe}$; (c) qualitative and (d) quantitative EELS line profiles showing the distribution of $\mathrm{O}, \mathrm{Cr}$, and $\mathrm{Fe}$.

To identify the preferred orientation of the oxide precipitates in the internal oxide layer, atomicresolution HAADF imaging was conducted. The magnified HAADF image in Fig. 9a shows the dispersed distribution of oxide precipitates in the internal oxide layer. Atomic-resolution image shows that the metal in the internal oxide layer had a Body-centred Cubic (BCC) structure (Fig. 9b). The related Fast Fourier Transform (FFT) pattern shows that the atomic-resolution image was captured at the zone axis of [001] (Fig. 9c). According to the FFT pattern, the oxides were revealed to preferentially precipitate along the $<001>$ orientations.

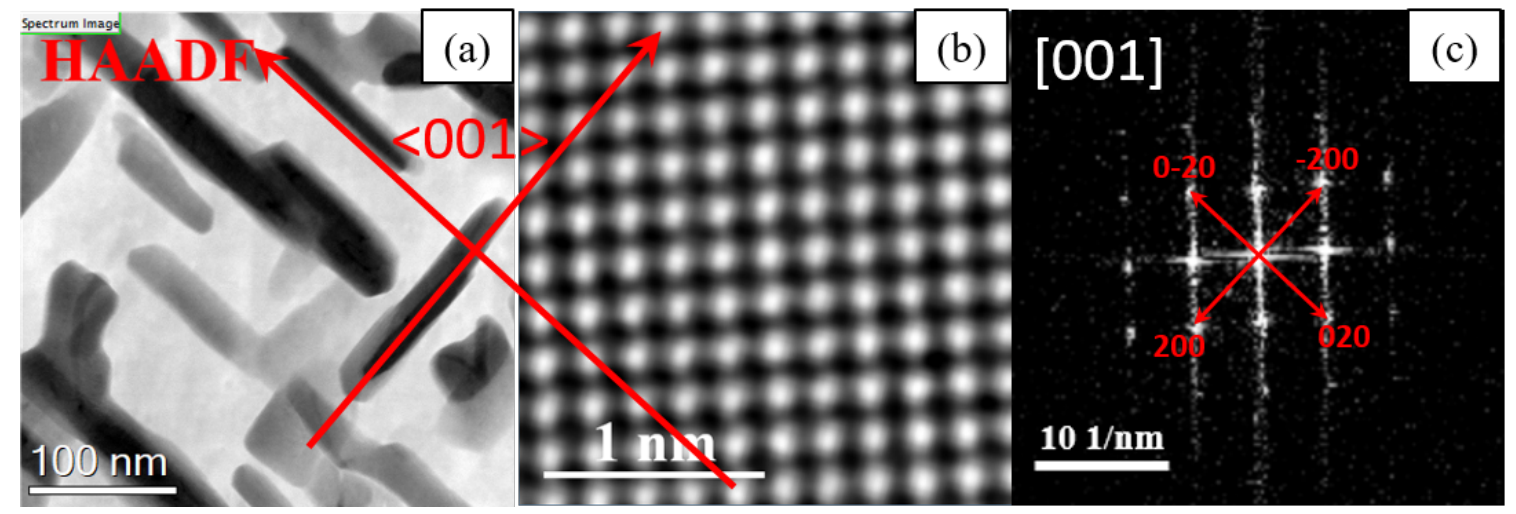

Figure 9. Identification of the preferential orientation of oxide precipitation in the internal oxide layer: a) HAADF image; b) atomic-resolution image of BCC metal; c) FFT pattern.

\section{(c) Internal-inner oxide layers interface}

Region 3 was around the interface between the internal and inner oxide layers, which was around 2 $\mu \mathrm{m}$ away from Region 2. As shown in Fig. 10a, the left-half and right-half of Region 3 represented a part of internal and inner oxide layers, respectively. Compared with Region 2, the left-half in Region 3 had suffered a longer time of oxidation. The oxides in this region were still discrete and are needleshaped, which were consistent with the observations made in Region 2. Furthermore, preferential oxide precipitation was also observed, which was also revealed to be along the $<001>$ orientations. EELS signal intensity maps in Fig. 10b show that the oxide precipitates were also enriched in $\mathrm{Cr}$ and depleted in Fe. However, compared with the sharp precipitate-metal interfaces in Region 2, the precipitatemetal interfaces in the left-half of Region 3 appeared to be blurred, suggesting that the metal surrounding the oxide precipitates in the left-half of Region 3 might have been oxidized. This hypothesis can be supported by the O-map in Fig. 10b, in which a better contrast is presented. It is worth noting that the newly formed oxide surrounding the prior oxide precipitates contained much lower $\mathrm{Cr}$ compared with chromite (Figs. 10c and d). This could be due to the prior formation of chromite precipitates consuming most of $\mathrm{Cr}$ in the surrounding matrix (Figs. $7 \mathrm{c}$ and $8 \mathrm{c}$ ). Due to the lack of $\mathrm{Cr}$ after forming $\mathrm{FeCr}_{2} \mathrm{O}_{4}$, the newly formed oxide was supposed to be composed of $\mathrm{Fe}_{3-\mathrm{x}} \mathrm{Cr}_{\mathrm{x}} \mathrm{O}_{4}$, with " $\mathrm{x}$ " ranging between 0 and 2 .

The inner oxide layer in the right-half of Region 3 had been fully oxidized and no metal was observed, suggesting that this layer of oxide was continuous (Fig. 10a). However, this layer appears to be very porous due to the existence of a large number of cavities. EELS signal intensity maps show that 
although the inner oxide layer was continuous, the distribution of chemical composition was not uniform (Fig. 10b). Further observation on the Cr-map and Fe-map shows that the distribution of $\mathrm{Cr}$ and $\mathrm{Fe}$ in the inner oxide layer was very similar to that in the internal oxide layer. The positions and preferential precipitation orientations of the prior chromite precipitates can still be observed, although all the surrounding metal had been oxidized. The existence of the similarly oriented Cr-rich oxide precipitates in the fully oxidized inner oxide layer suggested that further oxidation of the internal oxide layer mainly consumed the surrounding metal and the prior $\mathrm{Cr}$-rich oxide precipitates were not significantly affected. EELS quantitative line-scan shows that although the concentrations of Fe and $\mathrm{Ni}$ in the inner oxide layer were different, the concentration of $\mathrm{O}$ was nearly constant, which was around 57 at.\%. As a result, the oxides in the inner oxide layer can be described as $\mathrm{M}_{3} \mathrm{O}_{4}$ (" $\mathrm{M}$ " represents $\mathrm{Fe}$ and $\mathrm{Cr}$ ). The $\mathrm{Cr}$-rich oxide precipitates in the inner oxide layer was supposed to be the same with that in the internal oxide layer, which was chromite. The surrounding Cr-depleted oxides can also be described as $\mathrm{Fe}_{3-\mathrm{x}} \mathrm{Cr}_{\mathrm{x}} \mathrm{O}_{4}$. Due to the overlap of the different phases in the inner oxide layer, the exact chemical composition of the Cr-rich oxide precipitates and surrounding Cr-depleted oxides cannot be measured by EELS.

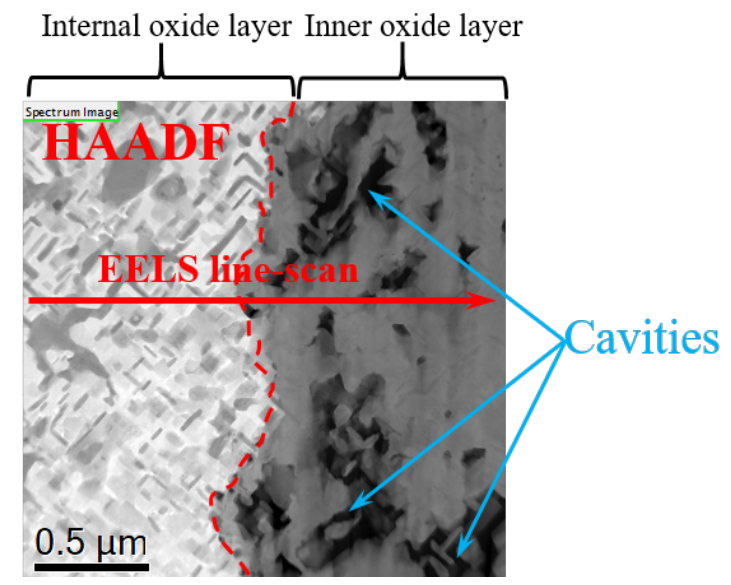

(a)

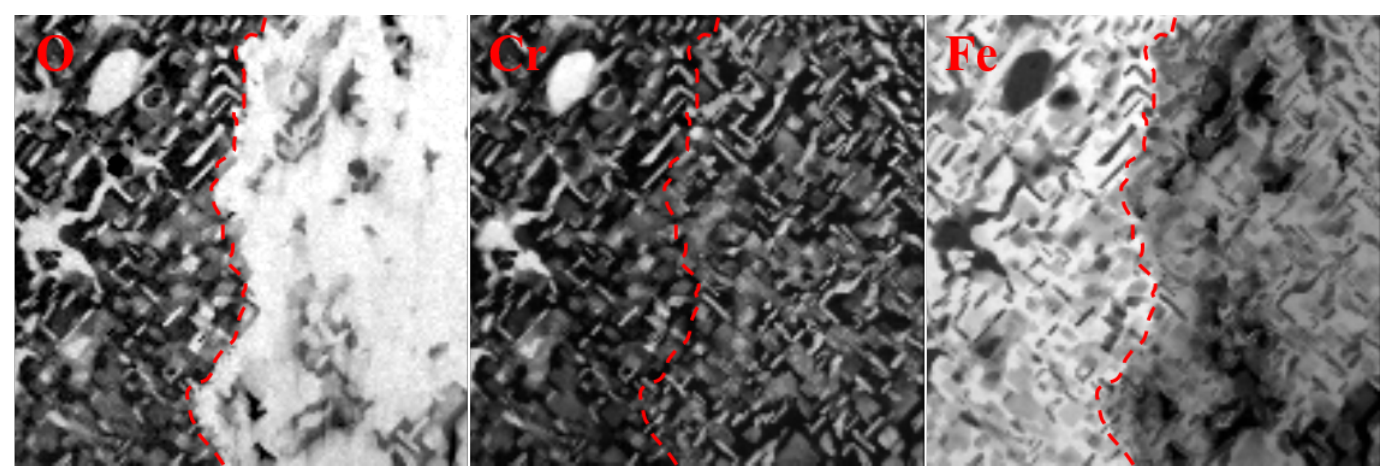

(b) 


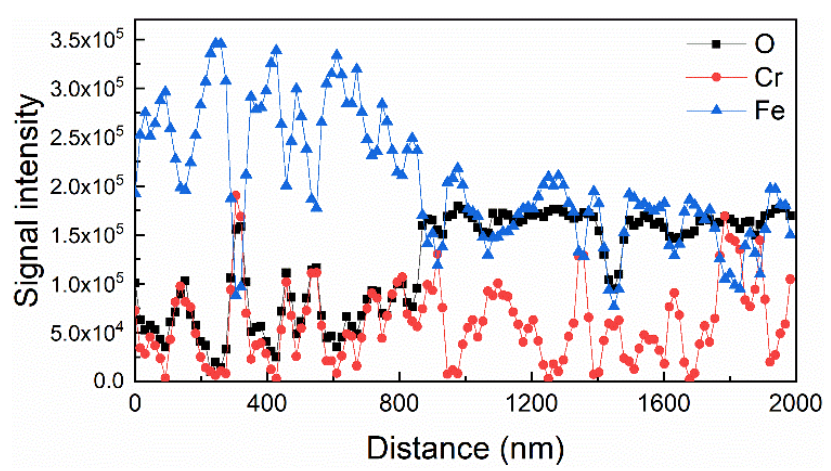

(c)

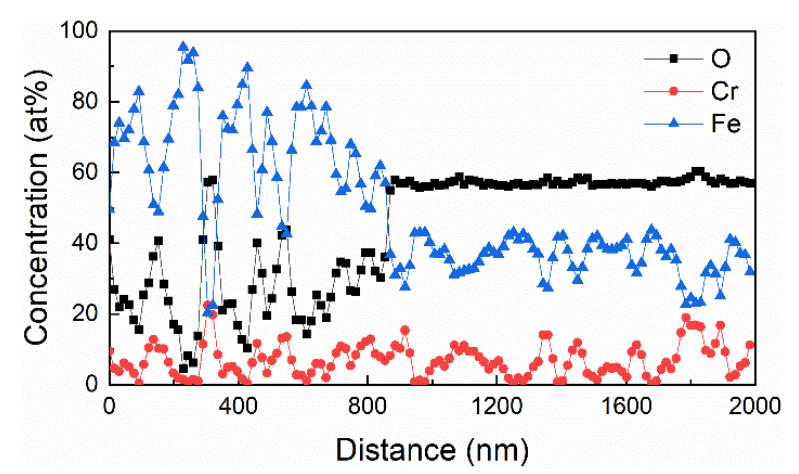

(d)

Figure 10. Morphology and chemical composition distribution around the internal-inner oxide layers interface (TEM sample 1, Region 3). (a) HAADF image showing the morphology around the internalinner oxide layers interface; (b) qualitative EELS chemical composition mapping showing the distribution of $\mathrm{O}, \mathrm{Cr}$, and $\mathrm{Fe}$; (c) qualitative and (d) quantitative EELS line profiles showing the distribution of $\mathrm{O}, \mathrm{Cr}$, and $\mathrm{Fe}$.

\section{(d) Inner oxide layer}

Region 4 was around $7 \mu \mathrm{m}$ away from the internal-inner oxide layers interface. Compared with the right-half in Region 3, the inner oxide layer examined in Region 4 had suffered a longer time of oxidation. Fig. 11a shows that there were also many cavities in the inner oxide layer. The O-map shows that the inner oxide layer had been fully oxidized and no metal was observed (Fig. 11b). Both the Crmap and Fe-map show that the distribution of chemical composition was not uniform, which was very similar to that in the right-half of Region 3. According to the signal intensity contrasts in the Cr-map and Fe-map, the positions and preferential precipitation orientations of the prior oxide precipitates appeared to be still observable (Fig. 11b). The EELS line profiles further confirmed the fluctuation of the chemical composition distribution in the inner oxide layer (Figs. 11c and d). Since the chemical composition in Region 4 was very similar to that in the right-half of Region 3, it suggested that the inner oxide layer was stable and further exposure would not change the chemical composition distribution.

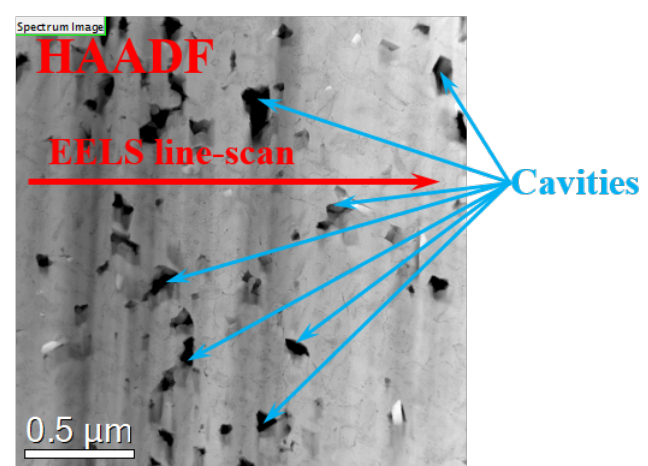

(a) 


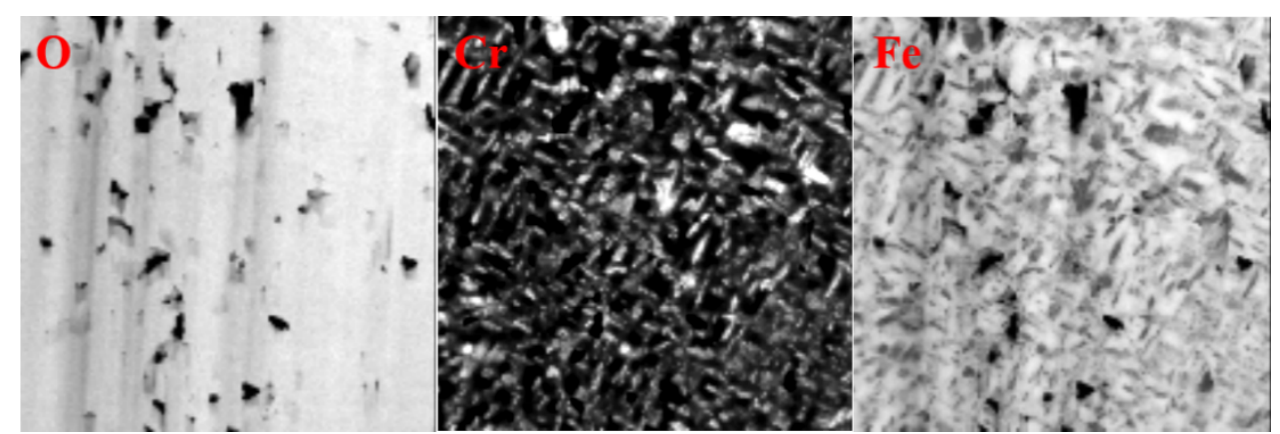

(b)

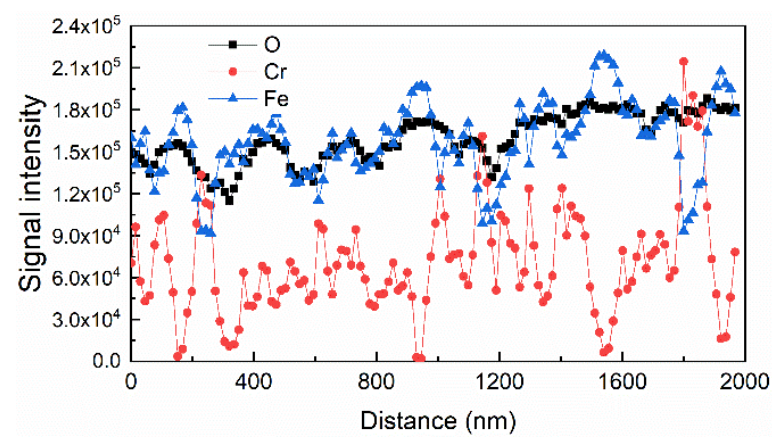

(c)

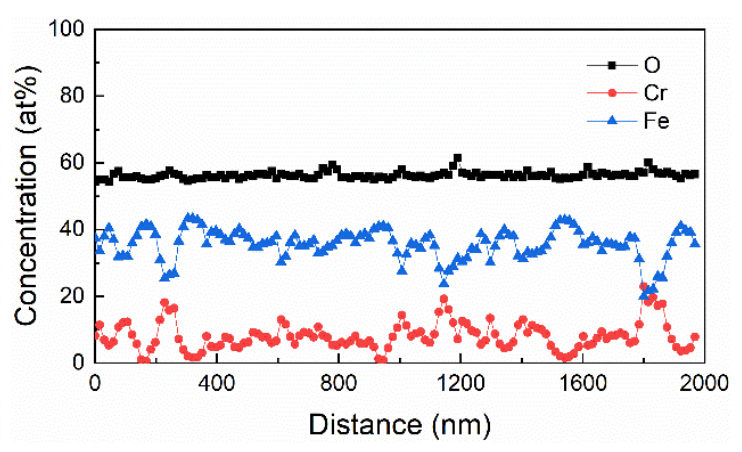

(d)

Figure 11. Morphology and chemical composition distribution in the inner oxide layer (TEM sample 2, Region 4). (a) HAADF image showing the morphology in the inner oxide layer; (b) qualitative EELS chemical composition mapping showing the distribution of $\mathrm{O}, \mathrm{Cr}$, and $\mathrm{Fe}$; (c) qualitative and (d) quantitative EELS line profiles showing the distribution of $\mathrm{O}, \mathrm{Cr}$, and $\mathrm{Fe}$.

\subsubsection{Chemical composition analysis by APT}

As mentioned above, it is difficult to measure the chemical composition in the small features by ATEM due to the potential overlap issues. Thus, APT analysis was conducted on six needles prepared from the internal and inner oxide layers (three for each) to overcome the spatial overlap issues caused by the ATEM analysis. Fig. 12a shows the 3-dimentional (3D) elemental distribution in one of the representative needles prepared from the internal oxide layer. The enrichment of $\mathrm{Cr}$ in the oxide precipitates was also observed. To quantify the chemical composition in the oxide precipitates and the surrounding metal, a line-profile was extracted from the region across the precipitate-metal interface (see O-map in Fig. 12a). It is seen that there was nearly no $\mathrm{Cr}$ (lower than $0.5 \%$ ) in the metal surrounding the Cr-rich oxide precipitates, although a certain amount of $\mathrm{Cr}$ was detected by EELS (Figs. 7 and 8), which was likely due to the TEM projection overlap. The chemical composition measured in the $\mathrm{Cr}$-rich oxide precipitates was 52.0 at.\% O, 31.5 at.\% $\mathrm{Cr}$, and 16.5 at.\% Fe. With a $\mathrm{Cr}: \mathrm{Fe}$ ratio of $1.91: 1$ the measured composition was very close to a stoichiometric chromite spinel $\mathrm{FeCr}_{2} \mathrm{O}_{4}$ (Fig. 12b), which was consistent to the results obtained from ATEM analysis (Figs. 7 and 8). There was a deficit in O measured within the chromite. A "loss" of oxygen during APT evaporation has previously been observed, documented, and tentatively explained [53-56]. 


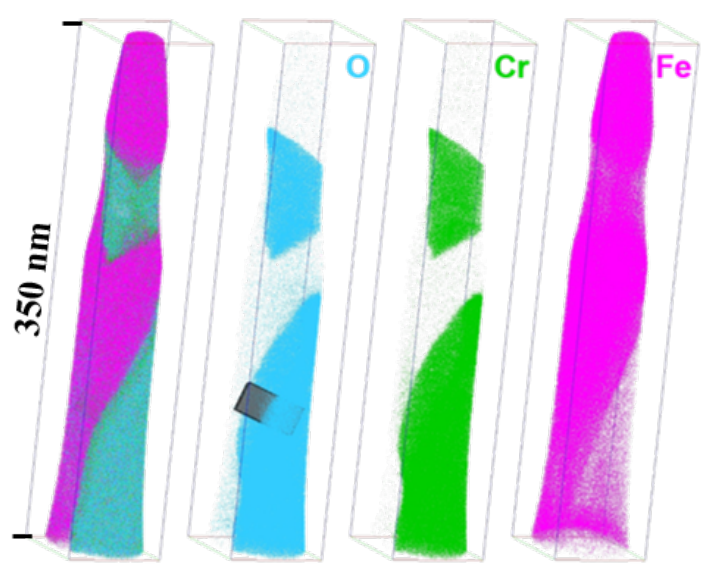

(a)

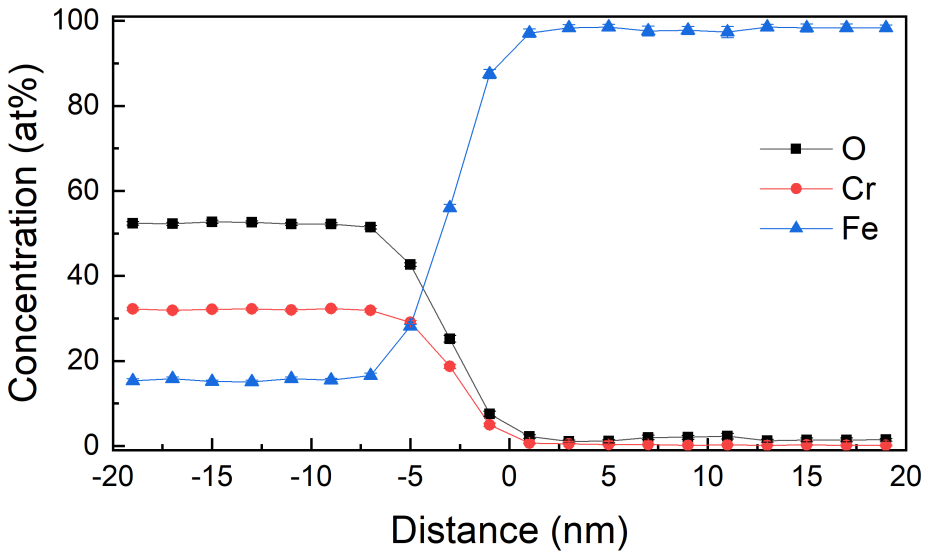

(b)

Figure 12. (a) APT data set showing the 3D chemical composition distribution in the chromite precipitates and surrounding metal in the internal oxide layer; (b) concentration profiles across the chromite-metal interface.

Fig. 13a shows the 3D elemental distribution in one of the representative needles prepared from the inner oxide layer. $\mathrm{O}$ was observed everywhere, suggesting that the inner oxide layer had been fully oxidized and no metal phase existed. Cr enrichment was also observed in the inner oxide layer, which was consistent with the results observed in EELS (Figs. 10 and 11). The chemical composition measured in the $\mathrm{Cr}$-rich oxide precipitates was 53.0 at.\% O, 31.0 at.\% $\mathrm{Cr}$, and 16.0 at.\% Fe, with a $\mathrm{Cr}$ : Fe ratio of $1.94: 1$ (Fig. 13b). This ratio was similar to that measured in the internal oxide layer, although $\mathrm{O}$ deficit also existed, suggesting that the Cr-rich oxide precipitates in the inner oxide layer were also chromite. Although a certain amount of $\mathrm{Cr}$ was detected by EELS in the oxides surrounding the Cr-rich oxide precipitates in the inner oxide layer, APT analysis showed that there was nearly no $\mathrm{Cr}$ (lower than 0.5\%) in these oxides. This difference is believed to be caused by TEM projection overlap and highlights the importance of using correlative techniques when characterising features on these length scales. In addition, this observation suggests that all $\mathrm{Cr}$ in the matrix had been consumed by forming the chromite precipitates and further oxidation mainly forms $\mathrm{Fe}$ oxides. Considering the low content of oxygen in the experimental environment, the Fe oxides were believed to be magnetite $\mathrm{Fe}_{3} \mathrm{O}_{4}$. Although the $\mathrm{Fe}: \mathrm{O}$ ratio measured from APT is different from that in the magnetite, which is also believed to be due to O deficit caused by APT [53-56].

According to the results above, the inner oxide layer mainly consisted of $\mathrm{FeCr}_{2} \mathrm{O}_{4}$ (Cr-rich precipitates) and $\mathrm{Fe}_{3} \mathrm{O}_{4}$ (Fe-depleted surrounding oxides). These two types of oxides should have an equal $\mathrm{O}$ concentration $(\sim 57 \%)$, which had been confirmed by EELS (Figs. 10d and 11d). However, the APT analysis showed an unequal $\mathrm{O}$ concentration in these two types of oxides. This discrepancy in $\mathrm{O}$ content in the APT data may be explained by the fact that the two oxide phases would be expected to have different evaporation fields. This difference in evaporation field would impact the degree of $\mathrm{O}$ "loss" by affecting the multiple event rate; a similar observation has been made in the analysis of carbides [57]. 


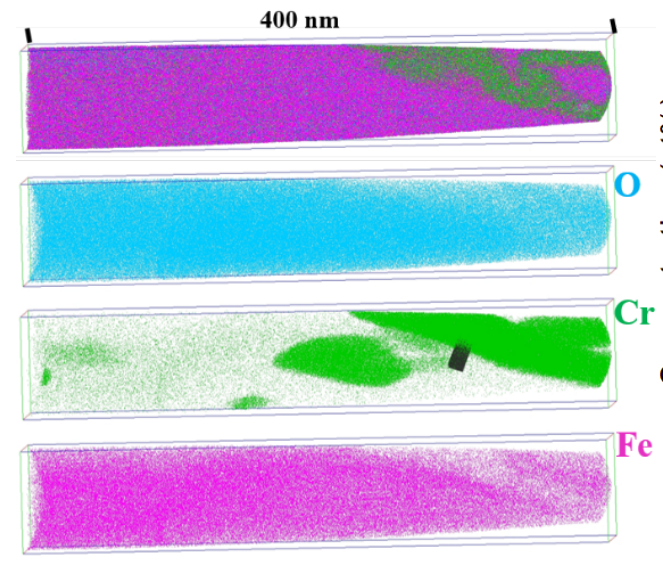

(a)

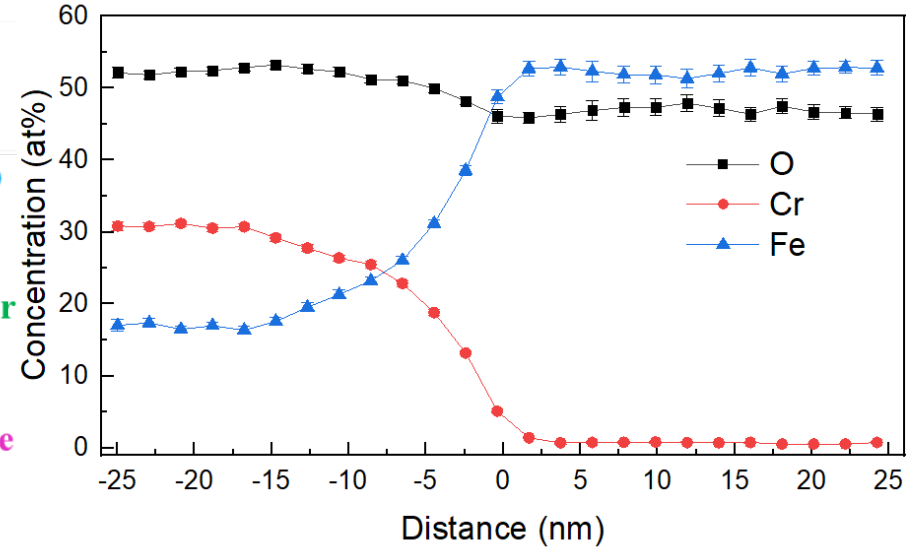

(b)

Figure 13. (a) APT data set showing the $3 \mathrm{D}$ chemical composition distribution in the $\mathrm{Cr}$-rich and $\mathrm{Cr}$ depleted oxides in the inner oxide layer; (b) concentration profiles across the interface of the $\mathrm{Cr}$-rich and $\mathrm{Cr}$-depleted oxides.

\subsubsection{Crystallographic analysis by on-axis TKD}

\section{(a) Internal oxide layer}

As shown in Figs. 7 and 8, needle-shape oxide precipitates were observed in the internal oxide layer. However, the growth of some of the oxide precipitates was observed to be preferentially oriented in the $<001>$ directions (Fig. 9) while the others appeared to have no preferential orientation under the HAADF examination (Fig. 7). Compared with HAADF, on-axis TKD can provide the crystallographic orientation information in 3D. Hence, on-axis TKD was conducted to study the crystallographic orientation relationship between the oxide precipitates and the surrounding metal matrix in the internal oxide layer.

A representative region around the internal oxide layer-matrix interface, in which the growth of the oxide precipitates appeared to be not preferentially oriented, was selected to conduct on-axis TKD analysis. According to the results presented above, the oxide precipitates in the inner oxide layer consisted of $\mathrm{FeCr}_{2} \mathrm{O}_{4}$, which had a Face Centred Cubic (FCC) structure. In contrast with the FCC structure of the oxide phase, the metal phase had a BCC structure. As a result, the oxide precipitates can be easily distinguished from the metal matrix by on-axis TKD. Fig. 14a shows the distribution of different phases in this region. The red and green pixels represented ferrite (metal matrix) and chromite (oxide precipitate), respectively. Due to the improved spatial resolution of the on-axis TKD [58-60], the oxide precipitates had been well-indexed. At first glance, it would seem that the oxide precipitates examined in this region had no preferred orientation. Fig. 14b shows inverse pole figures (IPF) along the $\mathrm{x}$-axis (left), y-axis (middle), and z-axis (right), which are referred to as IPFX, IPFY, and IPFZ, respectively. In the IPF images, different colours represented different crystallographic orientations. The legends of the orientation triangles of ferrite and chromite are added in Fig. 14b. It is seen that the metal matrix had the same colour while the oxide precipitates had different colours, suggesting that the metal matrix in the examined region had the same crystallographic orientation (from the same grain) while the oxide precipitates had different crystallographic orientations. To examine the crystallographic orientation relationships between the oxide precipitates and their surrounding metal matrix, all oxide precipitates were analysed individually. Since the colours of the chromite in the IPFX image can be mainly divided into three groups, as highlighted by the black rectangles in the IPFX 
image, three representative different oriented oxide precipitates were selected to show their 3D crystallographic orientation relationships with their surrounding metal matrix. A careful analysis confirmed that all the oxide precipitates had the same crystallographic orientation relationship respect to their surrounding metal matrix, which can be described as $(001)_{\mathrm{FCC}} / /(001)_{\mathrm{BCC}}$ and $[001]_{\mathrm{FCC}} / /[110]_{\mathrm{BCC}}$, as shown in Fig. 14c.

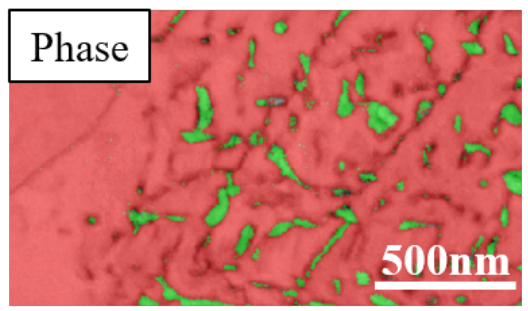

(a)

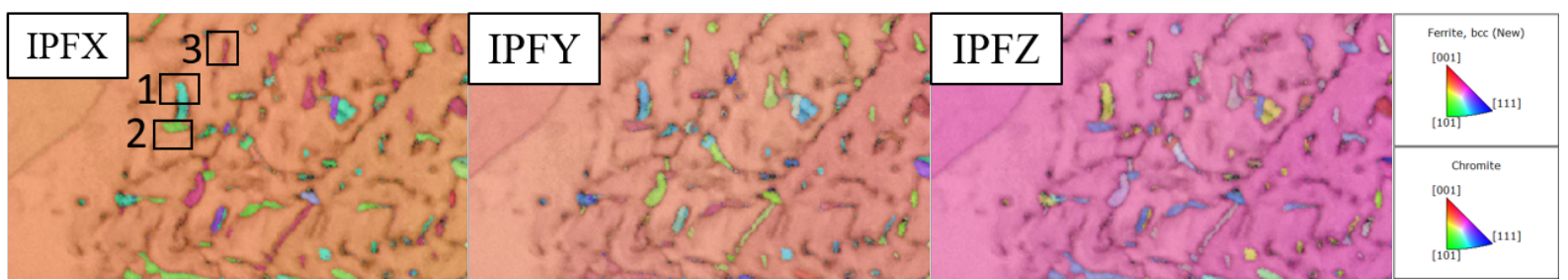

(b)

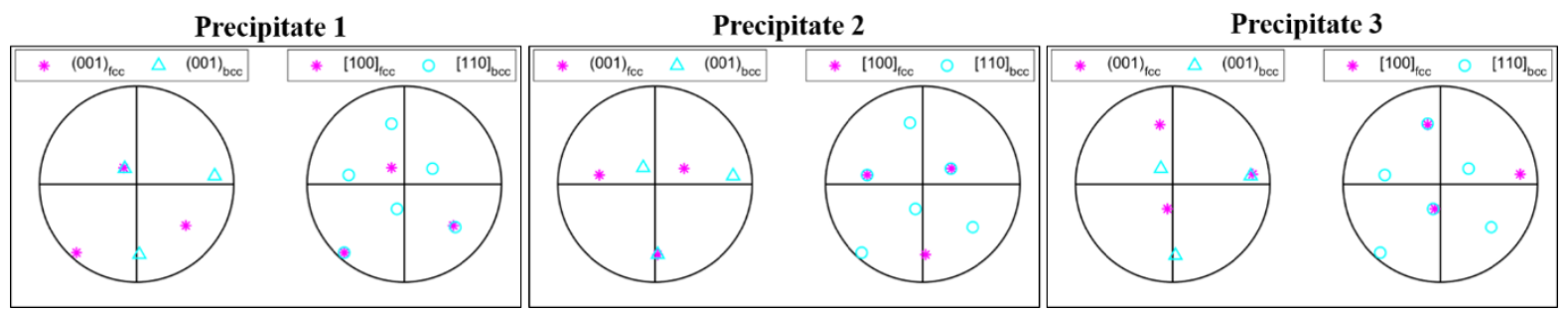

(c)

Figure 14. TKD analysis on the region around the internal oxide layer-matrix interface (step size $=5$ $\mathrm{nm}$ ). (a) Phase map (red and green pixels represent metal matrix and oxide precipitates, respectively); (b) IPF maps with orientation triangle legends; (c) pole figures of the three selected oxide precipitates with their surrounding metal matrix.

A representative region in the internal oxide layer, in which the growth of the oxide precipitates was preferentially oriented along the $<001>$ directions, was selected to conduct on-axis TKD analysis. As shown in Fig. 15a, both the oxide precipitates (green pixels) and metal matrix (red pixels) had been successfully indexed. Fig. $15 \mathrm{~b}$ shows that the metal matrix had the same crystallographic orientation, suggesting that the metal matrix examined in this region belonged to a same grain. In contrast, the oxide precipitates had different crystallographic orientations. Analysis of the crystallographic orientation relationships between the individual oxide precipitates and their surrounding metal matrix was also conducted. The results show that they all had the same crystallographic orientation relationships with their surrounding metal matrix. Three representative differently oriented oxide precipitates were selected to show their 3D crystallographic orientation relationships with their surrounding metal matrix. The regions of the three examined oxide precipitates were highlighted by the black rectangles in the IPFX image. As shown in Fig. 15c, the crystallographic orientation relationship was also identified as $(001)_{\mathrm{FCC}} / /(001)_{\mathrm{BCC}}$ and $[001]_{\mathrm{FCC}} / /[110]_{\mathrm{BCC}}$. 


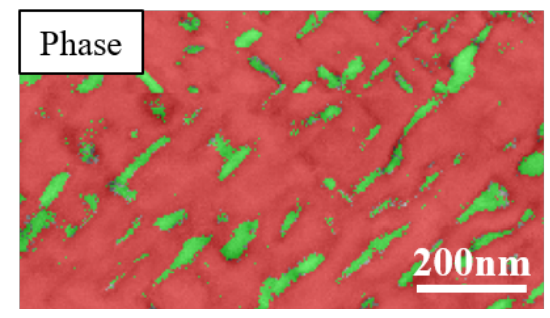

(a)

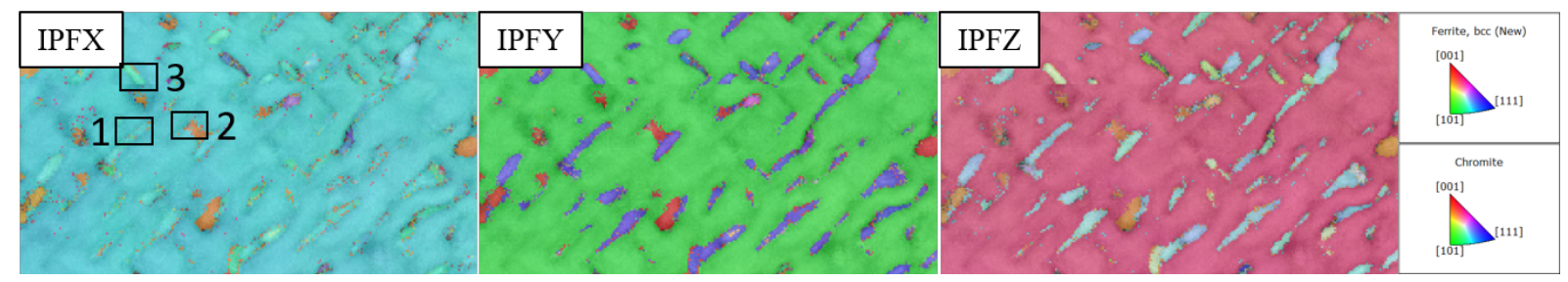

(b)

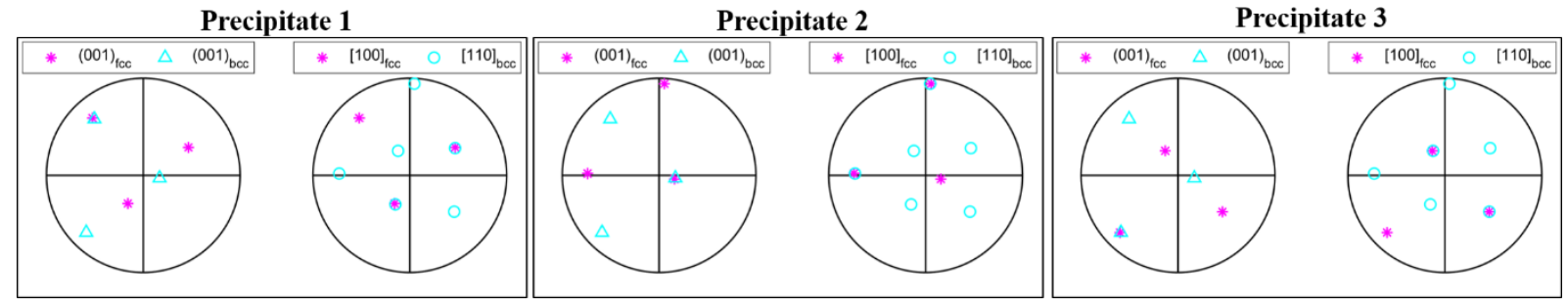

(c)

Figure 15. TKD analysis on the internal oxide layer (step size $=5 \mathrm{~nm}$ ). (a) Phase map (red and green pixels represent metal matrix and oxide precipitates, respectively); (b) IPF maps with orientation triangle legends; (c) pole figures of the three selected oxide precipitates with their surrounding metal matrix.

\section{(b) Inner oxide layer}

Although the inner oxide layer formed on the F-M steels after exposure to high-temperature environments has been generally reported to be composed of nano-sized equiaxed grains, the accurate crystallographic information of the inner oxide layers had not been well constructed due to the relatively poor spatial resolution of the traditional EBSD analysis (Fig. 5). Hence, on-axis TKD was also conducted on the inner oxide layer. According to the results presented above, the inner oxide layer was believed to be composed of chromite and magnetite. Since these two types of oxides had very similar lattice parameter, they cannot be distinguished by the Kikuchi patterns. As a result, all oxides in the inner oxide layer were identified as chromite-type spinel (Fig. 16a). The black pixels represented cavities in the inner oxide layer. Fig. 16b shows the grain shapes of the inner oxide layer. There were 542 grains in total in the examined region, with an average grain size of $480 \mathrm{~nm}$. The sizes of these oxide grains were very different, ranging from 30 to $830 \mathrm{~nm}$ (Fig. 16c). It is clearly shown that the oxide grains of the inner oxide layer were not equiaxed. On the contrary, the shapes of these grains were very irregular (Fig. 16b), which was very different from the results reported in the literature [1$3,10,13,15-20,34,35,41]$. The misunderstanding in the literature might be originated from the lack of resolution of their characterization techniques. The IPF images of the inner oxide layer showed that the oxide grains were not randomly oriented and predominant orientations can be observed (Fig. 16d). The pole figures in Fig. 16e further confirmed the existence of texture in the inner oxide layer. 


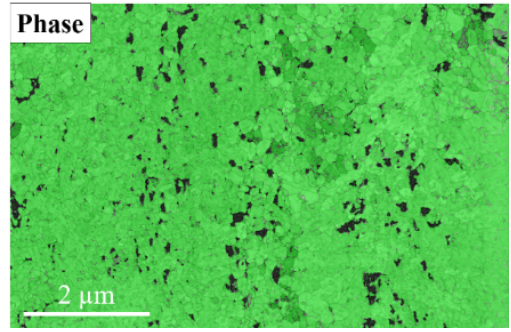

(a)

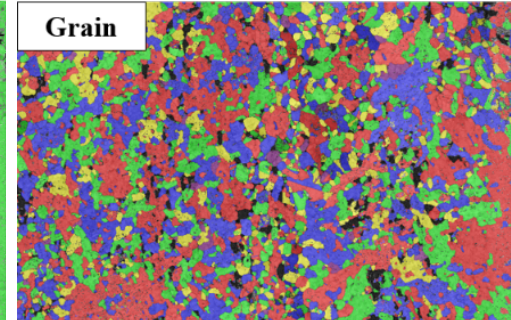

(b)

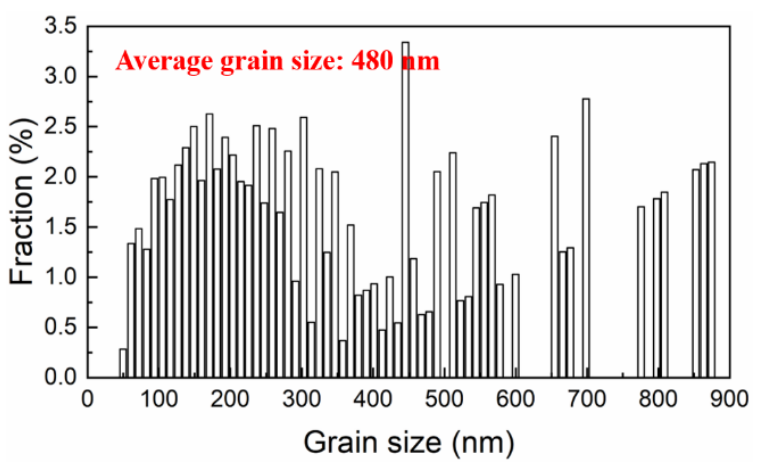

(c)

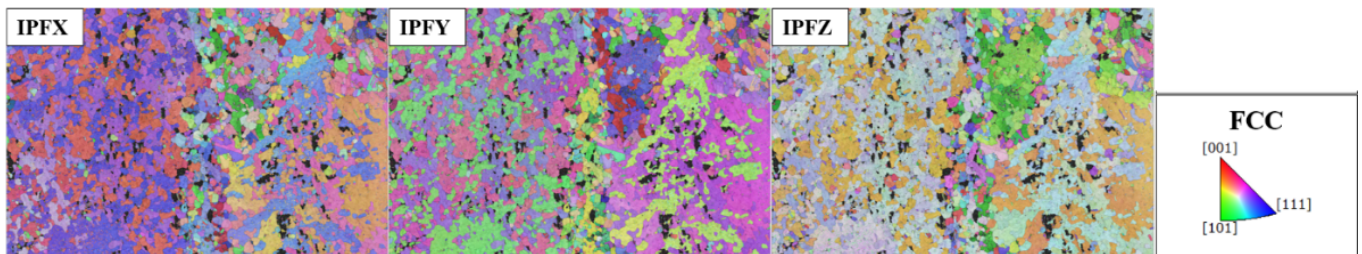

(d)
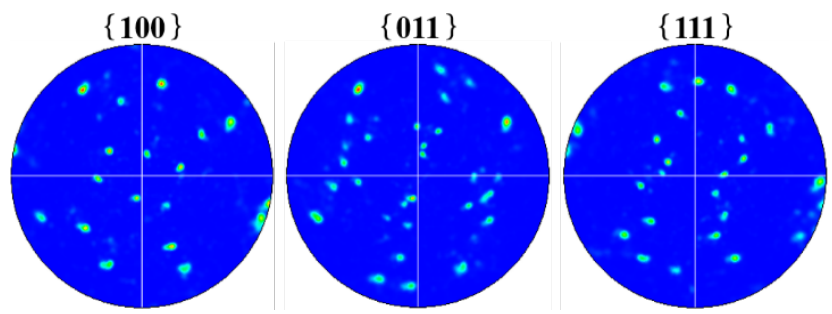

(e)

Figure 16. TKD analysis on the inner oxide layer (step size $=5 \mathrm{~nm}$ ). (a) Phase map (red and green pixels represent metal matrix and oxide precipitates, respectively); (b) grain shape map; (c) grain size distribution profile; (d) IPF maps with orientation triangle legend; (e) pole figures of the examined region.

\section{Discussion}

In this study, a triplex surface oxide film is observed on the Fe-9Cr F-M steel after exposure to the high-temperature steam. The oxides located at the different depths of the surface oxide film have been examined in detail by multiscale characterization techniques. To understand the evolution of chemical composition and crystallographic orientation of the oxides with the exposure time, we used the oxides prepared from different depths to represent the oxides formed at different stages during the exposure testing. For example, the internal oxide layer is used to represent the oxides formed at the early stage of oxidation and the inner oxide layer forms later by converting the prior internal oxide layer. In addition, we believe that the growth of the internal and inner oxide layers is a continuous process, or 
at least during our test $(1500 \mathrm{~h})$. This is because we always observe internal and inner oxide layers during the whole period of exposure. As shown in the supplementary materials, an internal and an inner oxide layers are also observed in the coupons after exposure for $600 \mathrm{~h}$ and $1500 \mathrm{~h}$ (Fig. S1). As a result, we believe that an internal oxide layer will form first after exposure to the high-temperature steam and an inner oxide layer will form afterwards, from the region formerly occupied by the internal oxide layer. With the increase of the exposure time, both the internal and inner oxide layers will grow gradually into the material. Based on the results presented above and in literature, the detailed formation mechanisms of the different oxide layers are proposed and discussed below.

\subsection{Current understanding of the oxidation mechanisms}

\subsubsection{The formation mechanisms of the internal oxide layer}

The existence of an internal oxide layer between the inner oxide layer and metal matrix has been frequently reported in F-M steels after exposure to high-temperature mediums, such as steam [1-3, 10, 14-20, 41, 61, 62], carbon dioxide [61, 63], and liquid metal [34, 35, 51]. The thickness of this layer varies with material composition, temperature, exposure time, and content of dissolved oxygen [1-3, $10,14-20,34,35,41,51,61-63]$. Unfortunately, the formation of this layer and its implication to the oxidation mechanisms of the F-M steel in high-temperature environments have not attracted enough attention. This might be due to the scale of the oxide precipitates, too small to be clearly observed and analysed by the traditional characterization techniques, such as EDX and EBSD equipped in SEM (Figs. 4 and 5). TEM analysis on this layer has been occasionally observed in the literature [15, 19, 20, $49,61,62]$. However, the TEM imaging conducted in these studies mainly worked under the TEM mode $[15,19,20,61,62]$, which cannot provide enough contrast to show the small features in detail. In addition, if the TEM foil is not thin enough $(<50 \mathrm{~nm})$, the overlap between the oxide precipitates and the surrounding metal will block the acquisition of useful information from the TEM analysis (a projection of a 3D volume onto a $2 \mathrm{D}$ plane). In this study, these problems have been overcome by the application of high-quality site-specific sample preparation with FIB, an aberration-correction scanning TEM (STEM), 3D APT, and an on-axis TKD, resulting in unprecedented high-quality data.

As shown in Figs. 7-11, an internal oxide layer forms after the material is exposed to the hightemperature steam. Instead of forming a continuous layer of oxide film, the oxides in this layer are dispersedly distributed. The oxide precipitates are enriched in $\mathrm{Cr}$ and depleted in $\mathrm{Fe}$, and the metal in this layer exhibits an opposite trend. The SEM-EDX line profiles show that the internal oxide layer has an equal amount of $\mathrm{Cr}$ to the unaffected metal matrix in a given volume (Fig. 4b). This suggests that the little or no diffusion of $\mathrm{Cr}$ occurs at this stage. Compared with the $\mathrm{Cr}$, there is a composition gradient of Fe decreasing outwards the material surface, suggesting a significant loss of Fe during the formation of the internal oxide layer. In addition, the existence of a composition gradient confirms that the loss of Fe follows a diffusion-based process. The EELS signal intensity Fe-map shows that the $\mathrm{Fe}$ atomic density in the metallic part of the inner oxide layer is nearly the same as the unaffected metal matrix, while the oxide precipitates contain lower Fe atomic density than the unaffected metal matrix. As a result, the loss of $\mathrm{Fe}$ in the internal oxide layer is mainly caused by the regions occupied by the oxide precipitates. Since the depletion of Fe is observed in all the oxide precipitates, it indicates that the diffusion of $\mathrm{Fe}$ in the internal oxide layer can occur at a much longer distance than the $\mathrm{Cr}$.

According to the discussion above, it is clear that the formation of the internal oxide layer is the result of inward diffusion of oxygen reacting with all $\mathrm{Cr}$ and a part of $\mathrm{Fe}$. Meanwhile, during the formation of oxide precipitates, part of the original matrix Fe diffuses out from the regions now occupied by the oxide precipitates. The oxide precipitates in the internal oxide layer have been identified as $\mathrm{FeCr}_{2} \mathrm{O}_{4}$. 
The formation of these type of oxides can be explained by the low oxygen partial pressure inside the metal matrix. According to the results reported in the literature [15, 20, 25, 35], with the increase of environmental oxygen partial pressure, the formation of different types of oxides in $\mathrm{Fe}-\mathrm{Cr}$ steels follows the sequence of $\mathrm{Cr}_{2} \mathrm{O}_{3}, \mathrm{FeCr}_{2} \mathrm{O}_{4}, \mathrm{Fe}_{3} \mathrm{O}_{4}$, and $\mathrm{Fe}_{2} \mathrm{O}_{3}$. Since the internal oxide layer is always located at the deepest region of the surface oxide film, the oxygen partial pressure in the internal oxide layer is initially assumed to be very low. According to the work conducted in [15], the formation of $\mathrm{Cr}_{2} \mathrm{O}_{3}$ is thermodynamically favoured under low oxygen partial pressure conditions. As a result, we believe that the oxide precipitates formed at the early stage belong to $\mathrm{Cr}_{2} \mathrm{O}_{3}$ instead of $\mathrm{FeCr}_{2} \mathrm{O}_{4}$. However, according to the results presented in present study, the oxide precipitates in the internal oxide layer were indexed as $\mathrm{FeCr}_{2} \mathrm{O}_{4}$ (Fig. 7e). We believe this is because the oxygen partial pressure in the internal oxide layer will increase gradually, which will convert the $\mathrm{Cr}_{2} \mathrm{O}_{3}$ to $\mathrm{FeCr}_{2} \mathrm{O}_{4}$ [15]. The reason why the oxide precipitates were observed in the internal oxide layer are mainly composed of $\mathrm{FeCr}_{2} \mathrm{O}_{4}$ might be due to this conversion process is quite fast. These oxide precipitates are also reported by many other researchers and they are also identified as $\mathrm{FeCr}_{2} \mathrm{O}_{4}[15,19,20,35,51,61,62]$. To protect the material from further oxidation, the formation of a continuous and compact oxide film is required. The internal oxide layer is not able to protect the material effectively since the unoxidized metal can still act as diffusion paths for the oxygen and metallic elements.

As shown in Fig. 5b, the nano-sized oxide precipitates in the internal oxide layer cannot be indexed by traditional EBSD due to its very limited spatial resolution. Due to the application of on-axis TKD, the statistical examination of the crystallographic orientation relationship between the nano-sized oxide precipitates and their surrounding metal has been achieved for the first time. All the oxide precipitates observed in the internal oxide layer are identified to have the same crystallographic orientation relationship with their surrounding metal, which can be described as $(001)_{\mathrm{FCC}} / /(001)_{\mathrm{BCC}}$ and $[001]_{\mathrm{FCC}} / /[110]_{\mathrm{BCC}}$, as described by the Baker-Nutting orientation relationship, which is a typical relationship between FCC particles and their surrounding BCC matrix [64, 65]. Although this relationship has also been reported by previous researchers in the study of F-M steels after exposure to high-temperature liquid metal $[20,51]$, these authors only examined a very limited number of oxide precipitates due to the difficulties in tilting the TEM foils to the right zone axes. In the present study, more than 100 oxide precipitates have been examined and all of them show the Baker-Nutting orientation relationship. As a result, more statistically relevant conclusions can be made.

It is necessary to point it out that due to the large misfit along the $[001]_{\text {spinel }} / /[001]_{\text {ferrite, }}$ the growth of the oxide precipitates is reported to be preferentially oriented along the $<001>$ directions [20], which is consistent to the results observed in the present study (Figs. 8-10). However, the preferential growth orientation is not always observable (Fig. 7), which requires the observation surface is not too far away from the $\{001\}$ planes. Since the growth of the oxide precipitates in the internal oxide layer can be affected by the matrix orientation, it is supposed that the material oxidation rate can be affected by the crystallographic orientation of the exposed surface to the high-temperature medium.

\subsubsection{The formation mechanisms of the inner oxide layer}

Compared with the dispersed oxides formed in the internal oxide layer, the inner oxide layer is continuous. Due to the improved resolution of the ATEM analysis conducted in the current study, the oxides prepared from different depths of the inner oxide layer have been explicitly analysed to study the evolution of the inner oxide layer with the exposure time. Although the SEM-EDX line profiles show that the chemical composition in the inner oxide layer is generally uniform, its spatial resolution is limited. Indeed, the high-resolution ATEM analyses show a significant fluctuation of the chemical 
composition in the inner oxide layer. As shown in the supplementary materials (Fig. S1), the thickness of the inner oxide layer gradually increases with the exposure time and converts the prior internal oxide layer to inner oxide layer. The conversion from internal oxide layer to inner oxide layer can be observed in Fig. 10, in which the preferentially oriented Cr-rich oxide precipitates can be observed in both layers. Any remaining metallic $\mathrm{Fe}$ and $\mathrm{Cr}$ in the internal oxide layer have been oxidized, connecting the discretely distributed chromite precipitates during the conversion process and resulting in the formation of a continuous inner oxide layer. Due to the lack of $\mathrm{Cr}$ in the metal matrix in the internal oxide layer, the newly formed oxide during the conversion process is very likely to be $\mathrm{Fe}_{3} \mathrm{O}_{4}$ (Fig. 13).

It is well known that the spinel structure contains cations with two different oxidation states $(2+$ and $3+$ ) bonded with oxygen ions. The conversion from $\mathrm{Fe}_{3} \mathrm{O}_{4}$ to $\mathrm{Fe}_{3-\mathrm{x}} \mathrm{Cr}_{\mathrm{x}} \mathrm{O}_{4}(\mathrm{x}>0)$ occurs when $\mathrm{Cr}^{3+}$ replaces $\mathrm{Fe}^{3+}$ [66-68]. If $\mathrm{Cr}$ availability is low, $\mathrm{Cr}^{3+}$ replaces $\mathrm{Fe}^{2+}$ at the octahedral sites first. Once all the $\mathrm{Fe}^{2+}$ at the octahedral sites has been pushed to the tetrahedral sites, the conversion from an inverse $\mathrm{Fe}_{3} \mathrm{O}_{4}$ spinel to a normal $\mathrm{Fe}_{3-\mathrm{x}} \mathrm{Cr}_{\mathrm{x}} \mathrm{O}_{4}$ spinel is completed. Since the diffusion of $\mathrm{Fe}$ ions in the spinel is mainly through the octahedral sites, once the octahedral sites are occupied by the $\mathrm{Cr}^{3+}$, both the electron exchange and available diffusion paths for $\mathrm{Fe}$ ions are decreased, which could explain the better protectiveness of the spinel containing $\mathrm{Cr}\left(\mathrm{Fe}_{3-\mathrm{x}} \mathrm{Cr}_{\mathrm{x}} \mathrm{O}_{4}\right)$ than the $\mathrm{Fe}_{3} \mathrm{O}_{4}$ [19]. Due to the relatively low $\mathrm{Cr}$ content in the matrix, there are not enough $\mathrm{Cr}^{3+}$ ions to fill all octahedral sites, which can be partially responsible for the poor protectiveness of the inner oxide layer. This has been linked with the existence of a large number of nano-cavities in this layer [67] (Figs. 10 and 11). As a result, the internal oxidation can propagate further into the matrix although the structure of the inner oxide layer is continuous.

Although the inner oxide layer has been proved to be nano-porous according to the results presented above (Figs. 10 and 11), the detailed formation mechanisms of the nano-cavities in the inner oxide layer is still unclear just based on the results in the present study. However, in a recent study [43], nano-cavities were also observed in the oxide formed on an austenitic alloy exposed to steam at $350^{\circ} \mathrm{C}$, while the nano-cavities were not observed when the same alloy was exposed to dry oxygen at $350^{\circ} \mathrm{C}$. The formation mechanisms of the nano-cavities were suggested to be due to the water dissociationinduced protons promoting the formation, migration, and clustering of both cation and anion vacancies. Since the water dissociation can also occur in the high-temperature steam environment, the theory proposed in [43] can also be used to explain the formation of nano-cavities in the inner oxide layer in the present study. These nano-cavities in the inner oxide layer can work as fast-diffusion paths once they are interconnected. The interconnected nano-cavities could allow the direct diffusion of water molecule from the environment into the inner oxide layer, resulting in an enhanced oxidation.

The SEM-EDX line profiles show that the inner and internal oxide layers nearly have the same volume concentration of $\mathrm{Cr}$ as the unaffected metal matrix (Fig. 4b), indicating that the diffusion of $\mathrm{Cr}$ can only occur locally. Once $\mathrm{Cr}$ is oxidized, it will be stabilized in the chromite. Compared with $\mathrm{Cr}$, the volume concentration of $\mathrm{Fe}$ in the inner oxide layer is lower than in the internal oxide layer. This suggests that, during the formation of the inner oxide layer, the outward diffusion of Fe occurs simultaneously, which is similar to that occurs in the internal oxide layer. In addition, the diffusion of Fe can also occur at a much longer distance than Cr. Since the volume concentration of Fe in the inner oxide layer is nearly uniform and no composition gradient is observed, it suggests that the outward diffusion of $\mathrm{Fe}$ in this layer is much faster than that occurring in the internal oxide layer.

Due to the improved resolution of the on-axis TKD conducted on the present study, the inner oxide layer has been identified as consisting of irregular nano-sized grains, instead of equiaxed grains widely 
reported in the literature $[1-3,10,13,15-20,34,35,41]$ (Fig. 16). As mentioned above, the formation of the inner oxide layer is believed to originate from the conversion of the internal oxide layer. The conversion process is complex, including both the chemical composition redistribution and oxide nano-recrystallization. Although the exact conversion process cannot be captured by an ex-situ approach, a direct comparison of the chemical composition distribution and crystallographic information between the internal and inner oxide layers may shed lights on the understanding of the dynamic conversion process. As seen in the internal oxide layer (in the region close to the internalinner oxide layers interface (Fig. 10b)), a part of the oxide precipitates has grown larger by consuming the surrounding metal. Due to the increase in the size of the oxide precipitates, some of the large oxide precipitates have already become interconnected in the internal oxide layer. As a result, it is reasonable to propose that the conversion from internal oxide layer to inner oxide layer is due to the gradual increase of the size of the dispersed oxide precipitates. Once all the surrounding metal has been consumed, then the continuous inner oxide layer forms. Although not all the oxide precipitates have the same crystallographic orientations, a part of the oxide precipitates indeed have the same crystallographic orientations. Once the same oriented oxide precipitates grow larger and are interconnected with each other, a much larger grain will form, which may explain the formation of the irregular grains in the inner oxide layer.

\subsubsection{The formation mechanisms of the outer oxide layer}

In contrast with the controversies over the formation mechanisms of the internal and inner oxide layers, consensus exists in the literature $[1-3,10,12-20,25,26,34,35]$ over the formation mechanisms of the outer oxide layer. It is widely believed that the formation of the outer oxide layer is due to the outward diffusion of $\mathrm{Fe}$ from the inner and internal oxide layers. According to the results obtained in the current study and in the literature, it is sensible to propose that, once the F-M steels are exposed to the hightemperature steam, Fe from the internal and inner oxide layers diffuses out and reacts with the oxygen at the outmost of the surface oxide film, forming a columnar $\mathrm{Fe}_{3} \mathrm{O}_{4}$ outer oxide layer (Fig. 5b). It is reported that a high oxygen partial pressure environment favours the formation of a $\mathrm{Fe}_{2} \mathrm{O}_{3}$ layer at the outmost of the surface oxide film from the thermodynamic point of view [16, 69]. The absence of a $\mathrm{Fe}_{2} \mathrm{O}_{3}$ layer in the present study may be explained by the low content of dissolved oxygen in the hightemperature steam $(<10 \mathrm{ppb})$. Although the $\mathrm{Fe}_{3} \mathrm{O}_{4}$ outer oxide layer appears to be compact after $100 \mathrm{~h}$ of exposure, a large number of cavities and micro-cracks are observed after $600 \mathrm{~h}$ of exposure, as shown in Fig. S1. Similar phenomenon has also been reported by many other research groups $[15,16,19,25$, 61, 70-73]. As a result, the $\mathrm{Fe}_{3} \mathrm{O}_{4}$ outer oxide layer is generally believed to be non-protective. The formation mechanisms of the cavities and micro-cracks in the $\mathrm{Fe}_{3} \mathrm{O}_{4}$ outer oxide layer have been widely studied in the literature [12, 25, 74], and will not be discussed in this study.

\subsection{The controlling oxidation mechanisms: "available space model" vs. "internal oxidation model"}

Inspired by the isotope tracer studies conducted by Atkinson and Smart [75], the available space model was firstly proposed by Robertson and Manning [76] to explain the formation of a double-layered surface oxide film under high-temperature carbon dioxide. Although not referred to as the available space model, similar models had already been proposed much earlier by many other researchers in the study of metal oxidation in high-temperature carbon dioxide [77-79]. Following the work conducted by Robertson and Manning [76], the available space model was also proposed by Cory and Herrington $[80,81]$ to explain the formation of a double-layered surface oxide film under high-temperature steam. After a more detailed characterization of the surface oxide film, the available space model was 
reviewed and further developed by Martinelli et al. [34, 35, 52, 61, 62] and Bischoff et al. [19, 20, 41, 70]. The available space model generally believes that the metallic cations diffuse across the oxide scale from the inner oxide layer-metal matrix interface, which leaves behind vacancies and pores at the interface, where this "available space" will be used to form new $\mathrm{Cr}$-Fe spinel oxide. In addition, in this model, both the outer and inner oxide layers are believed to be formed in the manner of external oxidation.

Since the construction of the available space model is mainly based on the experimental observations, the phenomenological details might not be correctly accounted for due to the lack of characterization resolution. The key point in the available space model is that it suggests that the growth of the inner oxide layer can only occur within the nano-metric cavities at the inner oxide layer-metal matrix interface. However, according to the results obtained in the present study and in the literature $[1-3,10$, $17,19,20,51]$, a third oxide layer indeed exists between the inner oxide layer and the metal matrix. The existence of the third oxide layer indicates that the growth of the new oxide can occur beyond the inner oxide layer-metal matrix interface, suggesting that the "available space" is not necessarily required for the growth of new oxide. The thickness of this oxide layer is normally several microns, and needs to be taken into account since it proves oxygen lattice diffusion and the formation of an internal oxide, contrary to what suggested by the available space model.

Due to the unprecedented combination of complementary characterization technique utilised in the present study, it is clear to see that the growth of the new oxide is not just limited at the inner oxide layer-metal matrix interface but has developed into the region beyond the interface. The formation of the dispersed oxide precipitates in this layer is a typical characteristic of internal oxidation. Internal oxidation is the process in which oxygen dissolves in a metal and diffuses inwards, reacting with the less-noble solute to form dispersed metal oxide precipitates [4, 5]. Although high-temperature internal oxidation has been known for many decades, it was not until 1959 that a theory, based on a diffusioncontrolled process, was proposed by Carl Wagner to formally address the mechanisms driving this phenomenon [82]. According to Carl Wagner's original theory [82], two critical conditions have to be met before the internal oxidation can occur. The first one is that the content of oxygen needs to be low and only less-noble elements can be oxidized. The second one is that the concentration of less-noble element is lower than a critical value so that a continuous layer of oxide cannot form. However, in most practical applications of susceptible alloys under high-temperature environments, an internal oxide zone can be observed below an external noble element oxide scale [83]. Since the internal oxidation can still occur when the noble element can be oxidized, it suggests that the first condition is not necessarily required for the occurrence of internal oxidation. Based on these observations, Carl Wagner's original theory has been further developed by the following researchers [84-90]. Although the internal oxidation in combination of external scale formation has been extensively reported in different binary alloys, the microstructure of the surface oxide film varies from alloy to alloy. These different types of surface oxide film have been reviewed and classified by Rapp [83]. Among these different types of surface oxide film, the microstructure of the surface oxide film formed on $\mathrm{Ni}-\mathrm{Cr}$ dilute alloys shares the greatest similarities with the surface oxide film observed in the current study, consisting of an external noble element oxide layer $\left(\mathrm{NiO}\right.$ vs. $\left.\mathrm{Fe}_{3} \mathrm{O}_{4}\right)$ and internal noble-less noble elements spinel oxide layer $\left(\mathrm{NiCr}_{2} \mathrm{O}_{4}\right.$ vs. $\left.\mathrm{FeCr}_{2} \mathrm{O}_{4}\right)$. Differences between these two cases also exist. There is a continuous inner oxide layer between the external scale and the internal scale in the current study, while the inner oxide layer is absent in the $\mathrm{Ni}-\mathrm{Cr}$ dilute alloys. Although the inner oxide layer is continuous after $100 \mathrm{~h}$ of exposure, the observation of similar $\mathrm{Cr}$ enrichment in the inner oxide layer with the internal oxide layer (Fig. 10b) suggests that formation mechanism of the inner oxide layer is 
completely different from that of the outer oxide layer. Instead of external oxidation, the formation of the inner oxide layer is due to the further inward diffusion of oxygen into the internal oxide layer, leading to the further growth of dispersed oxide precipitates until connecting to each other and forming a continuous layer.

According to the results discussed above, the available space model fails to explain the observed internal oxidation. The formation of the inner oxide layer has been identified to be due to further internal oxidation instead of external oxidation. In addition, if the available space model is the controlling mechanism, the chemical composition in the inner oxide layer should be uniform [19], which contradicts the two oxides (Fe- and $\mathrm{Cr}$-rich) observed in this layer. Since all these phenomena are coherent with the internal oxidation in combination with external scale formation in Ni-Cr dilute alloys [83], a mechanism which better describes the observed microstructure can be proposed, based on an internal oxidation model. As a result, the controlling mechanism of Fe-Cr F-M steels in hightemperature steam is identified to be internal oxidation instead of available space model. A more accurate understanding of the high-temperature oxidation in steam may offer new pathways to remedy the corrosion-related failures in this environment.

\section{Conclusions}

The surface oxide film formed on an Fe-9Cr F-M steel after exposure to high-temperature steam at $600^{\circ} \mathrm{C}$ for $100 \mathrm{~h}$ has been studied by multiscale characterization techniques. The formation mechanisms of each oxide layer have been analysed in detail. The controlling oxidation mechanisms of F-M steels in high-temperature steam are also discussed. The main findings can be summarized as follows:

1. A triplex instead of duplex surface oxide film is observed: outer oxide layer, inner oxide layer, and internal oxide layer. Although the outer and inner oxide layers are continuous, the internal oxide layer is not and consists of oxide and metal phases. These three oxide layers are observed during the whole testing period (up to $1500 \mathrm{~h}$ ), suggesting that they are growing simultaneously after exposure to the high-temperature steam.

2. The Cr-rich oxide precipitates in the internal oxide layer are identified as $\mathrm{FeCr}_{2} \mathrm{O}_{4}$ chromite. The growth of these oxide precipitates is preferentially oriented along the $<001>$ directions. All the oxide precipitates have been shown to have the same crystallographic orientation relationship with their surrounding metal, which can be described as $(001)_{\mathrm{FCC}} / /(001)_{\mathrm{BCC}}$ and $[001]_{\mathrm{FCC}} / /[110]_{\mathrm{BCC}}$, as per the Baker-Nutting orientation relationships.

3. The formation of the inner oxide layer is believed to be the result of further growth of the Cr-rich oxide precipitates in the internal oxide layer, connecting with each other and forming a continuous oxide layer since preferentially oriented $\mathrm{Cr}$-rich oxide precipitates observed in the internal oxide layer still exist in the inner oxide layer. The prior formation of $\mathrm{Cr}$-rich oxide precipitates nearly consumes all $\mathrm{Cr}$ in the matrix so the further growth of the oxide precipitates is mainly by oxidizing remaining $\mathrm{Fe}$ into $\mathrm{Fe}_{3} \mathrm{O}_{4}$ magnetite. The average grain size of the inner oxide layer is $\sim 480 \mathrm{~nm}$. The inner oxide layer is made of irregular grains instead of equiaxed grains.

4. The outer-inner oxide layers interface coincides with the original specimen surface. The formation of the columnar outer oxide layer is the result of outward diffusion of Fe from the inner and internal oxide layers. The structure of the outer oxide layer is porous, which is believed to provide very limited protection to the underneath matrix. 
5. The available space model can neither explain the chemical composition fluctuation in the inner oxide layer nor the formation of the internal oxide layer. The internal oxide model is proposed to be the controlling oxidation mechanism of F-M steels in high-temperature steam.

\section{Acknowledgments}

The authors from Shanghai Jiao Tong University are grateful to the National Key Research and Development Program of China (YS2018YFE010246) for the financial support. The authors from University of Oxford would like to thank the EPSRC (EP/K040375/1, EP/N010868/1 and EP/R009392/1) grants for funding this research. Zhao Shen is grateful to China Scholarship Council (CSC) for providing PhD studentship.

\section{References}

[1] C. Cabet, F. Dalle, E. Gaganidze, J. Henry, H. Tanigawa, Ferritic-martensitic steels for fission and fusion applications. J. Nucl. Mater., 523(2019) 510-537.

[2] I.G. Wright, R.B. Dooley, A review of the oxidation behaviour of structural alloys in steam. Int. Mater. Rev., 55(2010) 129-167.

[3] S.R.J. Saunders, M. Monteiro, F. Rizzo, The oxidation behaviour of metals and alloys at high temperatures in atmospheres containing water vapour: A review. Prog. Mater. Sci., 53(2008) 775-837.

[4] N. Birks, G.H. Meier, F.S. Pettit, Introduction to the high temperature oxidation of metals. Cambridge University Press, 2006.

[5] D.J. Young, High temperature oxidation and corrosion of metals. Vol. 1., Elsevier, 2008.

[6] C. Cawthorne, E. Fulton, Voids in irradiated stainless steel. Nature, 216 (1967) 575-576.

[7] R. Viswanathan, J. Sarver, J.M. Tanzosh, Boiler materials for ultra-supercritical coal power plants — steam side oxidation. J. Mater. Eng. Perform., 15(2006) 255-274.

[8] F. Abe, Precipitate design for creep strengthening of 9\% Cr tempered martensitic steel for ultrasupercritical power plants. Sci. Technol. Adv. Mater., 9(2008) 013002.

[9] S.J. Zinkle, G.S. Was, Materials challenges in nuclear energy. Acta Mater., 61(2013) 735-758.

[10] G.S. Was, P. Ampornrat, G. Gupta, S. Teysseyre, E.A. West, T.R. Allen, K. Sridharan, L. Tan, Y. Chen, X. Ren, C. Pister, Corrosion and stress corrosion cracking in supercritical water. J. Nucl. Mater., 371(2007) 176-201.

[11] Y. Behnamian, A. Mostafaei, A. Kohandehghan, B.S. Amirkhiz, J. Li, W. Zheng, D. Guzonas, M. Chmielus, W. Chen, J.L. Luo, Characterization of oxide layer and micro-crack initiation in alloy 316L stainless steel after $20,000 \mathrm{~h}$ exposure to supercritical water at $500^{\circ} \mathrm{C}$. Mater. Charact., 131(2017), 532-543.

[12] Y. Li, T. Xu, S. Wang, J. Yang, B. Fekete, J. Yang, A. Wu, J. Qiu, Y. Xu, D.D. Macdonald, Predictions and Analyses on the Growth Behavior of Oxide Scales Formed on Ferritic-Martensitic in Supercritical Water. Oxid. Met., 92(2019) 27-48.

[13] X. Guo, Y. Fan, W. Gao, R. Tang, K. Chen, Z. Shen, L. Zhang, Corrosion resistance of candidate cladding materials for supercritical water reactor. Ann. Nucl. Energy, 127(2019) 351-363. 
[14] L. Zhang, Y. Bao, R. Tang, Selection and corrosion evaluation tests of candidate SCWR fuel cladding materials. Nucl. Eng. Des., 249(2012) 180-187.

[15] L. Tan, X. Ren, T.R. Allen, Corrosion behavior of 9-12\% Cr ferritic-martensitic steels in supercritical water. Corros. Sci., 52(2010) 1520-1528.

[16] Y. Chen, K. Sridharan, T. Allen, Corrosion behavior of ferritic-martensitic steel T91 in supercritical water. Corros. Sci., 48(2006) 2843-2854.

[17] K. Yin, S. Qiu, R. Tang, Q. Zhang, L. Zhang, Corrosion behavior of ferritic/martensitic steel P92 in supercritical water. J. Supercrit. Fluids, 50(2009) 235-239.

[18] L. Tan, M.T. Machut, K. Sridharan, T.R. Allen, Corrosion behavior of a ferritic/martensitic steel HCM12A exposed to harsh environments. J. Nucl. Mater., 371(2007) 161-170.

[19] J. Bischoff, A.T. Motta, Oxidation behavior of ferritic-martensitic and ODS steels in supercritical water. J. Nucl. Mater., 424(2012) 261-276.

[20] J. Bischoff, A.T. Motta, EFTEM and EELS analysis of the oxide layer formed on HCM12A exposed to SCW. J. Nucl. Mater., 430(2012) 171-180.

[21] I. Betova, M. Bojinov, P. Kinnunen, V. Lehtovuori, S. Peltonen, S. Penttilä, T. Saario, Composition, structure, and properties of corrosion layers on ferritic and austenitic steels in ultrasupercritical water. J. Electrochem. Soc., 153(2006) B464-B473.

[22] R. Viswanathan, J.F. Henry, J. Tanzosh, G. Stanko, J. Shingledecker, B. Vitalis, R. Purgert, US program on materials technology for ultra-supercritical coal power plants. J. Mater. Eng. Perform., 14(2005) 281-292.

[23] W.H. Yeo, A.T. Fry, J. Purbolaksono, S. Ramesh, J.I. Inayat-Hussain, H.L. Liew, M. Hamdi, Oxide scale growth and presumed exfoliation in a $700 \mathrm{C}$ or higher steam condition: A simulation study for future operations of ultra-supercritical power plants. J. Supercrit. Fluids, 92(2014) 215-222.

[24] R. Viswanathan, J. Sarver, J.M. Tanzosh, Boiler materials for ultra-supercritical coal power plants—steamside oxidation. J. Mater. Eng. Perform., 15(2006) 255-274.

[25] L. Sun, W. Yan, Estimation of oxidation kinetics and oxide scale void position of ferriticmartensitic steels in supercritical water. Adv. Mater. Sci. Eng., $2017(2017) 9154934$.

[26] N.Q. Zhang, H. Xu, B.R. Li, Y. Bai, D.Y. Liu, Influence of the dissolved oxygen content on corrosion of the ferritic-martensitic steel P92 in supercritical water. Corros. Sci., 56(2012) 123-128.

[27] B. Dooley, B. Larkin, L. Webb, F. Pocock, A. Bursik, Oxygenated treatment for fossil plants, Proceedings of 16th International Water Conference, vol. 53, Engineers Society of Western Pennsylvania, 1992.

[28] G.H. Meier, K. Jung, N. Mu, N.M. Yanar, F.S. Pettit, J.P. Abellán, T. Olszewski, L.N. Hierro, W.J. Quadakkers, G.R. Holcomb, Effect of alloy composition and exposure conditions on the selective oxidation behavior of ferritic Fe-Cr and Fe-Cr-X alloys. Oxid. Met., 74(2010) 319-340.

[29] G. Romeo, W. W. Smeltzer, J. S. Kirkaldy, Kinetics and Morphological Development of the Sulfide Scale on a Nickel-20 w/o Chromium Alloy in Hydrogen Sulfide-Hydrogen Atmospheres at $700^{\circ}$ C. J. Electrochem. Soc., 118(1971) 740-746. 
[30] G.B. Gibbs, A model for mild steel oxidation in $\mathrm{CO}_{2}$. Oxid. Met., 7(1973) 173-184.

[31] Y. Xie, J. Zhang, D.J. Young, Water vapour effects on corrosion of Ni-Cr alloys in $\mathrm{CO}_{2}$ gas at $650^{\circ}$ C. Corros. Sci., 136(2018) 311-325.

[32] L.F. He, P. Roman, B. Leng, K. Sridharan, M. Anderson, T.R. Allen, Corrosion behavior of an alumina forming austenitic steel exposed to supercritical carbon dioxide. Corros. Sci., 82(2014) 67-76.

[33] P. Hosemann, R. Dickerson, P. Dickerson, N. Li, S.A. Maloy, Transmission electron microscopy (TEM) on oxide layers formed on D9 stainless steel in lead bismuth eutectic (LBE). Corros. Sci., 66(2013) 196-202.

[34] L. Martinelli, F. Balbaud-Célérier, A. Terlain, S. Delpech, G. Santarini, J. Favergeon, G. Moulin, M. Tabarant, G. Picard, Oxidation mechanism of a $\mathrm{Fe}-9 \mathrm{Cr}-1 \mathrm{Mo}$ steel by liquid $\mathrm{Pb}-\mathrm{Bi}$ eutectic alloy (Part I). Corros. Sci., 50(2008) 2523-2536.

[35] L. Martinelli, F. Balbaud-Célérier, A. Terlain, S. Bosonnet, G. Picard, G. Santarini, Oxidation mechanism of an $\mathrm{Fe}-9 \mathrm{Cr}-1 \mathrm{Mo}$ steel by liquid $\mathrm{Pb}-\mathrm{Bi}$ eutectic alloy at $470 \mathrm{C}$ (Part II). Corros. Sci., 50(2008) 2537-2548.

[36] C. Wagner, The distribution of cations in metal oxide and metal sulphide solid solutions formed during the oxidation of alloys. Corros. Sci., 9(1969) 91-109.

[37] R. Dieckmann, Defects and cation diffusion in magnetite (IV): Nonstoichiometry and point defect structure of magnetite $\left(\mathrm{Fe}_{3-\delta} \mathrm{O}_{4}\right)$. Phys. Chem. Chem. Phys., 86(1982) 112-118.

[38] J. Topfer, S. Aggarwal, R. Dieckmann, Point defects and cation tracer diffusion in $\left(\mathrm{Cr}_{\mathrm{x}} \mathrm{Fe}_{1-\mathrm{x}}\right)_{3-}$ ${ }_{\delta} \mathrm{O}_{4}$ spinels. Solid State Ionics, 81 (1995) 251-266.

[39] A. Atkinson, Surface and interface mass transport in ionic materials. Solid State Ionics, 2830 (1988) 1377-1387.

[40] J. Robertson, The mechanism of high temperature aqueous corrosion of stainless steels. Corros. Sci., 32 (1991) 443-465.

[41] J. Bischoff, A.T. Motta, C. Eichfeld, R.J. Comstock, G. Cao, T.R. Allen. Corrosion of ferriticmartensitic steels in steam and supercritical water. J. Nucl. Mater., 441(2013) 604-611.

[42] A. Brückman, The mechanism of transport of matter through the scales during oxidation of metals and alloys. Corros. Sci., 7 (1967) 51-59.

[43] L. Luo, M. Su, P. Yan, L. Zou, D.K. Schreiber, D.R. Baer, Z. Zhu, G. Zhou, Y. Wang, S.M. Bruemmer, Z. Xu, Atomic origins of water-vapour-promoted alloy oxidation. Nat. Mater., 17(2018) 514-518.

[44] A. Pratt, L. Lari, O. Hovorka, A. Shah, C. Woffinden, S.P. Tear, C. Binns, R. Kröger, Enhanced oxidation of nanoparticles through strain-mediated ionic transport. Nat. Mater., 13(2014) 26-30.

[45] D.G. Xie, Z.J. Wang, J. Sun, J. Li, E. Ma, Z.W. Shan, In situ study of the initiation of hydrogen bubbles at the aluminium metal/oxide interface. Nat. Mater., 14(2015) 899-903.

[46] A. King, G. Johnson, D. Engelberg, W. Ludwig, J. Marrow, Observations of intergranular stress corrosion cracking in a grain-mapped polycrystal. Science, 321(2008) 382-385. 
[47] N. Mortazavi, C. Geers, M. Esmaily, V. Babic, M. Sattari, K. Lindgren, P. Malmberg, B. Jönsson, M. Halvarsson, J.E. Svensson, I. Panas, Interplay of water and reactive elements in oxidation of alumina-forming alloys. Nat. Mater., 17(2018) 610-617.

[48] M. Meisnar, S. Lozano-Perez, M. Moody, J. Holland, Low-energy EDX-A novel approach to study stress corrosion cracking in SUS304 stainless steel via scanning electron microscopy. Micron, 66(2014) 16-22.

[49] A. J. London, AtomProbeLab. https://sourceforge.net/projects/atomprobelab/ (2019)

[50] A. J. London, Quantifying Uncertainty from Mass-Peak Overlaps in Atom Probe Microscopy. Microsc. Microanal., 25 (2019) 378-388.

[51] Z. Ye, P. Wang, H. Dong, D. Li, Y. Zhang, Y. Li, Oxidation mechanism of T91 steel in liquid lead-bismuth eutectic: with consideration of internal oxidation. Sci. Rep-UK, 6(2016) 35268.

[52] F. Rouillard, G. Moine, L. Martinelli, J.C. Ruiz, Corrosion of 9Cr steel in CO2 at intermediate temperature I: mechanism of void-induced duplex oxide formation. Oxid. Met., 77(2012) 27-55.

[53] M. Bachhav, R. Danoix, F. Danoix, B. Hannoyer, S. Ogale, F. Vurpillot, Investigation of wüstite $\left(\mathrm{Fe}_{1-\mathrm{x}} \mathrm{O}\right)$ by femtosecond laser assisted atom probe tomography. Ultramicroscopy, 111(2011) 584-588.

[54] M. Tsukada, H. Tamura, K.P. McKenna, A.L. Shluger, Y.M. Chen, T. Ohkubo, K. Hono, Mechanism of laser assisted field evaporation from insulating oxides. Ultramicroscopy, 111(2011) 567-570.

[55] K. Kruska, S. Lozano-Perez, D.W. Saxey, T. Terachi, T. Yamada, G.D. Smith, Nanoscale characterisation of grain boundary oxidation in cold-worked stainless steels. Corros. Sci., 63(2012) 225-233.

[56] A. La Fontaine, H.W. Yen, P.J. Felfer, S.P. Ringer, J.M. Cairney, Atom probe study of chromium oxide spinels formed during intergranular corrosion. Scripta Mater., 99(2015) 1-4.

[57] M. Thuvander, J. Weidow, J. Angseryd, L.K. Falk, F. Liu, M. Sonestedt, K. Stiller, H.O. Andrén, Quantitative atom probe analysis of carbides. Ultramicroscopy, 111(2011) 604-608.

[58] J. Liu, S. Lozano-Perez, A.J. Wilkinson, C.R. Grovenor, On the depth resolution of transmission Kikuchi diffraction (TKD) analysis. Ultramicroscopy, 205(2019) 5-12.

[59] Z. Shen, M. Meisnar, K. Arioka, S. Lozano-Perez, Mechanistic understanding of the temperature dependence of crack growth rate in alloy 600 and 316 stainless steel through high-resolution characterization. Acta Mater., 165(2019) 73-86.

[60] Z. Shen, J. Liu, K. Arioka, S. Lozano-Perez, On the role of intergranular carbides on improving the stress corrosion cracking resistance in a cold-worked alloy 600. J. Nucl. Mater., 514(2019) 50-55.

[61] L. Martinelli, C. Desgranges, F. Rouillard, K. Ginestar, M. Tabarant, K. Rousseau, Comparative oxidation behaviour of Fe-9Cr steel in $\mathrm{CO} 2$ and $\mathrm{H} 2 \mathrm{O}$ at $550 \mathrm{C}$ : Detailed analysis of the inner oxide layer. Corros. Sci., 100(2015) 253-266.

[62] M.C. Demizieux,, C. Desgranges, L. Martinelli, J. Favergeon, K. Ginestar, Morphology and Buckling of the Oxide Scale after Fe-9Cr Steel Oxidation in Water Vapor Environment. Oxid. Met., 91(2019) 191-212. 
[63] F. Rouillard, T. Furukawa, Corrosion of 9-12Cr ferritic-martensitic steels in high-temperature CO2. Corros. Sci., 105 (2016)120-132.

[64] H.W. Yen, C.Y. Chen, T.Y. Wang, C.Y. Huang, J.R. Yang, Orientation relationship transition of nanometre sized interphase precipitated $\mathrm{TiC}$ carbides in $\mathrm{Ti}$ bearing steel. Mater. Sci. TechLond., 26(2010) 421-430.

[65] S. Shanmugam, R.D.K. Misra, T. Mannering, D. Panda, S.G. Jansto, Impact toughness and microstructure relationship in niobium-and vanadium-microalloyed steels processed with varied cooling rates to similar yield strength. Mater. Sci. Eng. A-Struct., 437(2006) 436-445.

[66] J. Töpfer, S. Aggarwal, R. Dieckmann, Point defects and cation tracer diffusion in $(\mathrm{CrxFe} 1-\mathrm{x})$ 3- $\delta$ O4 spinels. Solid State Ionics, 81(1995) 251-266.

[67] T. Terachi, T. Yamada, T. Miyamoto, K. Arioka, Role of grain boundary oxidation on PWSCC initiation influence of chemical compositions and stress. INSS Journal, 18(2011)137-151.

[68] R. Dieckmann, Defects and cation diffusion in magnetite (IV): Nonstoichiometry and point defect structure of magnetite (Fe3- $8 \mathrm{O} 4)$. Phys. Chem. Chem. Phys., 86 (1982) 112-118.

[69] L. Tan, Y. Yang, T.R. Allen, Oxidation behavior of iron-based alloy HCM12A exposed in supercritical water. Corros. Sci., 48(2006) 3123-3138.

[70] J. Bischoff, A.T. Motta, R.J. Comstock, Evolution of the oxide structure of 9CrODS steel exposed to supercritical water. J. Nucl. Mater., 392(2009) 272-279.

[71] D. Gómez-Briceño, F. Blázquez, A. Sáez-Maderuelo, Oxidation of austenitic and ferritic/martensitic alloys in supercritical water. J. Supercrit. Fluids, 78(2013) 103-113.

[72] X. Zhong, X. Wu, E.H. Han, Effects of exposure temperature and time on corrosion behavior of a ferritic-martensitic steel P92 in aerated supercritical water. Corros. Sci., 90(2015) 511-521.

[73] D. Laverde, T. Gomez-Acebo, F. Castro, Continuous and cyclic oxidation of T91 ferritic steel under steam. Corros. Sci., 46(2004) 613-631.

[74] P. Kofstad, On the formation of porosity and microchannels in growing scales. Oxid. Met., 24(1985) 265-276.

[75] A. Atkinson, D.W. Smart, Transport of nickel and oxygen during the oxidation of nickel and dilute nickel/chromium alloy. J. Electrochem. Soc., 135(1988) 2886-2893.

[76] J. Robertson, M.I. Manning, Criteria for formation of single layer, duplex, and breakaway scales on steels. Mater. Sci. Tech-Lond., 4(1988) 1064-1071.

[77] G.B. Gibbs, A model for mild steel oxidation in $\mathrm{CO}_{2}$. Oxid. Met., 7(1973) 173-184.

[78] M.G.C. Cox, B. McEnaney, V.D. Scott, A chemical diffusion model for partitioning of transition elements in oxide scales on alloys. Philos. Mag., 26(1972) 839-851.

[79] M.R. Taylor, J.M. Calvert, D.G. Lees, D.B. Meadowcroft, The mechanism of corrosion of Fe-9\% Cr alloys in carbon dioxide. Oxid. Met., 14(1980) 499-516.

[80] N.J. Cory, T. Herrington, The location of hydrogen in the kinetics of oxidation of ferrous alloys by superheated steam. Oxid. Met., 29(1988) 135-152. 
[81] L. Tomlinson, N.J. Cory, Hydrogen emission during the steam oxidation of ferritic steels: kinetics and mechanism. Corros. Sci., 29(1989) 939-965.

[82] C. Wagner, Reaktionstypen bei der Oxydation von Legierungen. Z. Elektrochem., 63(1959), 772782.

[83] R.A. Rapp, Kinetics, Microstructures and mechanism of internal oxidation-its effect and prevention in high temperature alloy oxidation. Corrosion, 21(1965) 382-401.

[84] F. Gesmundo, F. Viani, Transition from internal to external oxidation for binary alloys in the presence of an outer scale. Oxid. Met., 25(1986) 269-282.

[85] D.L. Douglass, A critique of internal oxidation in alloys during the post-Wagner era. Oxid. Met., 44(1995) 81-111.

[86] G.C. Wood, F.H. Stott, D.P. Whittle, Y. Shida, B.D. Bastow, The high-temperature internal oxidation and intergranular oxidation of nickel-chromium alloys. Corros. Sci., 23(1983) 9-25.

[87] F. H. Stott, G. C. Wood. Internal oxidation. Mater. Sci. Tech-Lond., 4(1988) 1072-1078.

[88] Y. Li, J.E. Morral, A local equilibrium model for internal oxidation. Acta Mater., 50(2002) 36833691.

[89] S.W. Guan, W.W. Smeltzer, Oxygen solubility and a criterion for the transition from internal to external oxidation of ternary alloys. Oxid. Met., 42(1994) 375-391.

[90] D.P. Whittle, Y. Shida, G.C. Wood, F.H. Stott, B.D. Bastow, Enhanced diffusion of oxygen during internal oxidation of nickel-base alloys. Philos. Mag. A, 46(1982) 931-949. 